\title{
Effect of roof-mounted solar panels on the wind energy exploitation on high-rise buildings
}

\author{
Francisco Toja-Silva ${ }^{a, b ; * ;}$, Carlos Peralta c, Oscar Lopez-Garcia ${ }^{\text {, }}$, Jorge Navarro ${ }^{a}$, \\ Ignacio Cruz ${ }^{\mathrm{a}}$ \\ a Centro de Investigaciones Energéticas, Medioambientales y Tecnológicas (CIEMAT), Av. Complutense 40, 28040 Madrid, Spain \\ ${ }^{b}$ Escuela Técnica Superior de Ingenieros Aeronáuticos, Universidad Politécnica de Madrid (UPM), Madrid, Spain \\ ' Fraunhofer IWES, Ammerlaender Heerstrasse 136, Oldenburg, Germany
}

A B S T R A C T

The analysis of the wind flow around buildings is of great interest in the field of renewable energies. This work presents an investigation of the effects of roof-mounted solar panels on the wind flow on building roofs, from the point of view of the wind energy exploitation. CFD simulations of the wind flow around an isolated building are performed with OpenFOAM. The simulations are compared with two wind tunnel experiments for validation: an isolated building and an array of solar panels. The wind flow on an empty roof is compared with roof-mounted solar panels cases. The solar panels are tested with tilt angles of $10^{\circ}$ and $30^{\circ}$, the most adequate inclination for solar panels in the Mediterranean region. The analysis is carried out both quantitatively and qualitatively. The full-scale building results are compared with a reduced-scale model and scaling issues are reported. The most adequate wind turbine for each roof region is suggested.

\section{Introduction}

The study of the wind in urban environments is of great interest in several different engineering applications (van Hooff and Blocken, 2010; Ramponi and Blocken, 2012; Blocken et al., 2012). Toja-Silva et al. (2013) presented a review of the opportunities and challenges for the urban wind energy exploitation that shows the necessity of an accurate analysis of the wind flow behaviour on building roofs. Some authors (Ledo et al. 2011; Lu and Ip, 2009; Ricciardelli and Polmeno, 2006; $\mathrm{Ng}$ et al, 2011; Abohela et al.. 2013) have studied the wind flow around different types of building shapes. A careful analysis must include both experimental and numerical investigations (Blocken, 2014).

Numerical investigations using computational fluid dynamics (CFD) are performed by using either Direct Numerical Simulations (DNS), Large-Eddy Simulations (LES) and Reynolds Averaged Navier-Stokes Equations (RANS), or a combination of the three. DNS with real atmospheric conditions is unapproachable, therefore simplifying assumptions must be made. These usually involve the turbulence modelling: LES and RANS. LES consists in the modelling of the near wall flow by using space filtered equations (Pope, 2000; Sagaut, 2006), usually leading to better agreement with experimental data than RANS, although its computational cost is very high for real cases (Franke et al., 2007). RANS is commonly used in combination with two-equation turbulence models. The choice of the turbulence model is a compromise between accuracy and computational cost.

Since the computational cost of LES with real-scale geometries is too expensive nowadays (Franke et al., 2007; Sumner et al, 2010), RANS modelling (especially in combination with the $k-\varepsilon$ model) is still widely used in industrial applications for complex cases. Some authors (Tominaga et al., 2008; Shao et al., 2012; Gousseau et al., 2013; Kono and Kogaki, 2013) have tested and validated different turbulence models by comparing numerical simulations with the experimental benchmark case $A$ of the Architectural Institute of Japan (http:/Wwwaij,or.jp/ipn/publish/ cffguide/index....htm), an isolated building of aspect ratio 1:1:2 tested in a wind tunnel by Meng and Hibi (1998). Toja-Silva et al. (2015) used this benchmark to analyse the wind flow on an empty building roof, and proposed the most appropriate position for 
different kinds of wind turbines (vertical and horizontal axis wind turbines).

The complementarity of different technologies and the stability of power generation is a crucial point for the use of renewable energy sources (Hong and Chen, 2014; Cheng et al., 2007). Solar and wind energies vary with time and energy management systems are usually necessary to adapt the time of energy conversion with the demand profile. However, both energy sources can be considered complementary. This complementarity varies with the daily solar cycle and the season. Solar irradiation is available during the day and during the night the wind energy supply is at its highest. In general, the availability of solar power is higher than wind in the summer, while the opposite is true in the winter (Liu and Wang, 2009). In a wind-solar hybrid system, one source of energy can offset the shortfall of the other (Huang et al., 2015), yielding a more stable generation system. Therefore, the motivation of the present work is to verify the compatibility of both wind and photovoltaic solar energy devices on a building roof from the point of view of the wind flow dynamics.

Some authors have carried out studies of ground-mounted (Shademan et al, 2014; Aly and Bitsuamlak, 2013) and roofmounted (Stathopoulos et al., 2014; Kopp et al., 2012; Pratt and Kopp, 2013) solar panels. These previous investigations focussed on the wind loads over the solar arrays (pressure coefficients). To the authors' knowledge, only the work of Pratt and Kopp (2013) presents data (velocity and Reynolds stresses) of the wind flow on the roof of a low-rise building. Complementarily, in the present investigation we will focus on a high-rise building, since the potential for both photovoltaic and wind energy devices is higher because the incident wind velocity is expected to be higher (considering exponential incident wind profiles) and the possibility of shadows caused by the neighbouring buildings is lower than in the case of a low-rise building (assuming that the neighbouring buildings are lower or at the same height). The definition of a high-rise building includes buildings higher than $23-30 \mathrm{~m}$ (or 510 storeys) (Craighead, 2009).

This work presents an analysis of the influence of roof-mounted solar panels on the wind energy exploitation, by studying the behaviour of velocity $(U)$ and turbulent kinetic energy $(k)$ on the roof and comparing both variables in a flat roof (without solar panels) with those in the same roof with solar panels installed. Two cases are analysed: the wind-tunnel reduced model studied in Toja-Silva et al. (2015) and an enlarged version of this building. blown up by a factor of 250 to match real scale dimensions. We use the turbulence model previously validated in the study by Toja-Silva et al. (2015), that focussed on the characteristics of the flow (velocity, turbulent kinetic energy, detachment, reattachment, recirculation, etc.) on the roof. The open source CFD software package OpenFOAM (http://www.openfoanucom) is used for the numerical investigation.

In the following, the governing equations and the turbulence modelling are explained in Section 2, the validation is presented in Section 3 and the cases studied are described in Section 4. Afterwards, Section 5 presents the results: discussion regarding the behaviour of $U$ and $k$ due to the presence of the solar panels on the roof, scaling issues, solution verification analysis and suggestion of the most adequate wind turbine model for each roof region. Finally, conclusions and recommendations for further studies are commented in section 6.

\section{Governing equations and turbulence modelling}

We solve the steady-state Reynolds Averaged Navier-Stokes (RANS) equations in the simulations performed in this study, which for an incompressible fluid without body forces are (Cheng (al. 2003)

$\frac{\partial \bar{u}_{i}}{\partial x_{i}}=0$

for mass conservation, and for momentum conservation

$\frac{\partial\left(\bar{u}_{i} \bar{u}_{j}\right)}{\partial x_{j}}=-\frac{1}{\partial} \frac{\partial \bar{p}}{\partial x_{i}}+\frac{\partial}{\partial x_{j}}\left(\nu \frac{\partial \bar{u}_{i}}{\partial x_{j}}-\overline{u_{i} u_{j}^{\prime}}\right)$

where $\bar{p}$ is the mean pressure and $\rho$ and $\nu$ are the fluid density and the kinematic viscosity, respectively. The Reynolds stresses $\overline{\left(u_{i} u_{j}^{\prime}\right)}$ are obtained from the mean flow values. Considering the Boussinesq linear isotropic eddy-viscosity hypothesis (linear relationship between turbulent stresses and mean velocity gradients), the statistical turbulence closure can be written as

$-\overline{u_{i} u_{j}^{\prime}}=2 \nu_{t} S_{i j}-\frac{2}{3} k \delta_{i j}$

where

$S_{i j}=\frac{1}{2}\left(\frac{\partial \bar{u}_{i}}{\partial x_{j}}+\frac{\partial \bar{u}_{j}}{\partial x_{i}}\right)$

is the strain rate tensor, $\nu_{t}$ is the kinematic eddy viscosity, $\delta_{i j}$ is the Kronecker Delta function and $k=\frac{1}{2} \overline{u_{i} u_{i}}$ is the turbulent kinetic energy. The steady-state equations for $k$ and the turbulence dissipation rate $(\varepsilon)$ without considering buoyancy are

$\frac{\partial\left(\bar{u}_{j} k\right)}{\partial x_{j}}=\frac{\partial}{\partial x_{j}}\left[\left(\nu+\frac{\nu_{t}}{\sigma_{k}}\right) \frac{\partial k}{\partial x_{j}}\right]+P_{k}-\varepsilon$

and

$\frac{\partial\left(\bar{u}_{j} \varepsilon\right)}{\partial x_{j}}=\frac{\partial}{\partial x_{j}}\left[\left(\nu+\frac{\nu_{t}}{\sigma_{\varepsilon}}\right) \frac{\partial \varepsilon}{\partial x_{j}}\right]+C_{\varepsilon: 1} \frac{\varepsilon}{k} P_{k}-C_{\varepsilon 2} \frac{\varepsilon^{2}}{k}$,

where $P_{k}$ is the production of $k$, and $\sigma_{k}$ and $\sigma_{\varepsilon}$ (Prandtl numbers), $C_{\varepsilon 1}$ and $C_{k 2}$ are closure constants. The production of $k$ in the standard $k-\varepsilon$ model (SKE) is

$P_{k}=\nu_{t} S^{2}$,

where $S$ is the modulus of the rate of strain tensor.

There are some modifications of the SKE model, developed to reduce the overestimation of $k$ at the impinging region of bluff bodies. Burbin (1996) proposed the following relationship between $\nu_{t}$ and the turbulence velocity time scale (T):

$\nu_{t}=C_{\mu} k T$.

where $C_{\mu}$ is a model coefficient for the turbulence model. Since in the SKE model $T_{S K E}=k / \varepsilon$ is adopted for $T$. Durbin (1996) proposed a bound in the time scale:

$T=\min \left(T_{S K E}, T_{D}\right)$,

where

$T_{D}=\frac{1}{3 C_{\mu} S} \sqrt{\frac{3}{2}}$

According to Dumbin (1996) Eq. (10) can be modified to obtain a better agreement with experimental data, and some authors have used slightly different versions of $T_{D}$ (Sumner, 2012; Tominaga et al. 2008). Tojamsilya at al (2015) have empirically found the following expression to obtain reasonable agreement of the recirculation distance on the building roof with the experimental data of Meng and Hibi (1998): 
$T_{D}=\frac{32}{45 C_{\mu} S}$

\section{Validation}

\subsection{Main flow validation}

We validate the main flow by studying the benchmark case $A$ of the Architectural Institute of Japan (http//www.aij.or.jp/jpn/publish/cfdguide/index e h(m). This benchmark case is an isolated building of aspect ratio 1:1:2 placed within an atmospheric boundary layer wind tunnel, tested by Meng and Hibi (1998). We have performed a validation of several 2-equation turbulence models in Toja-Silva er al. (2015) and, in what follows, we present a summary of this validation study. See Toja-Silva et al. (2015) for more details and for a deeper discussion about how the modified Durbin model (Eq. (II) was derived. Fig. 1 shows the geometry of the wind-tunnel building for the validation of the main flow. The geometry and the domain dimensions are set according to Tominaga et al. (2008).

We perform the simulations in OpenFOAM (http:/www. openfoam.com). Table 1 presents the boundary conditions imposed for all the variables at each boundary of the simulation domain. The inlet profiles, used in the wind tunnel experiment of Meng and Hibi (1998), are shown in Fig. 2. They are set in OpenFOAM with the utility setDiscreteFields (hup:/openfoamwikinet/ index.php/Contrib_sctDiscretcFiclds).

The steady-state simplefoam solver for incompressible turbulent flow is used to solve the partial differential equations (1) and (2). For the spatial discretisation of differential operators, the Gaussian integration was used with different interpolation schemes. The 2 nd order linear interpolation was applied for Gradient terms, the 2nd order upwind interpolation for Divergence terms, while for the Laplacian terms the 2 nd order linear interpolation was used with explicit non-orthogonal correction. Regarding the linear system solvers, generalised geometric-algebraic multi-grid solver (GAMG) with DIC smoother is used for the pressure, and preconditioned bi-conjugate gradient solver for asymmetric matrices (PBiCG) with diagonal incomplete LU (DILU) preconditioner is used for the rest of the variables. The convergence criterion is $10^{-5}$ for all the variables residuals.

Regarding the mesh, the external domain (inlet, outlet, ground, sky and sides in Fig. 1) is constructed using the blockMesh application in OpenFOAM with a grading of 4 in the vertical direction. The building geometry, previously designed with a CAD
Table 1

Boundary conditions imposed at each boundary of the domain following ittep:/

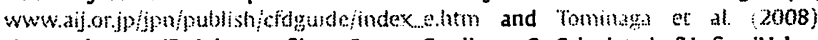
Nomenclature: iP, Inlet profile; $2 G$, zeroGradient: $C$, Calculated: $V$, fixedValue $w F$, wall function; sP, Symmetry plane (Tola-Siva et al., 2015).

\begin{tabular}{|c|c|c|c|c|c|}
\hline $\begin{array}{l}\text { Bound- } \\
\text { ary }\end{array}$ & $U$ & $k$ & $\varepsilon$ & $\nu_{t}$ & $p$ \\
\hline Inlet & iP & iP & iP & C & $z G$ \\
\hline Outlet & $\mathrm{zG}$ & & $\mathrm{zG}$ & C & fV zero \\
\hline Ground & fV zero & $\mathrm{kqR} w \mathrm{~F}$ & epsilon $w F$ & nutk rough wF & $\mathrm{zG}$ \\
\hline Building & fV zero & $\mathrm{kqR} w \mathrm{~F}$ & epsilon $w F$ & nutk WF & $z G$ \\
\hline Sky & fV zero & kqr wF & epsilon $w F$ & nutk rough wF & $2 G$ \\
\hline Sides & $\mathrm{sP}$ & $\mathrm{SP}$ & sP & sP & $s P$ \\
\hline
\end{tabular}

tool and saved in STL format, is embedded into the external mesh using the snappyHexMesh application. The mesh around the building is refined and adapted to its shape. The refinement distance around the building surfaces is $x / H=1$, where $x$ is the refinement distance and $H$ is the building height. The total number of cells in the final mesh is close to $3.1 \mathrm{M}$.

The turbulence is modelled using the modification of the Durbin $k-\varepsilon$ model presented in Toja-Silva et al. 2015) (explained in Section 2) with the coefficients proposed by (respo et al. (1985): $C_{\mu}=0.0333, C_{\varepsilon 1}=1.176, C_{\varepsilon 2}=1.92, \sigma_{k}=1.0, \sigma_{\varepsilon}=1.3$ and $\kappa=0.42$. These coefficients were obtained by crespo et al. (1985) from the atmospheric measurements of Panofsky and Dution (1984).

Since this investigation focuses on wind energy exploitation, we concentrate our analysis on the building roof. Therefore, the validation is carried out by comparing the mean wind velocity $(U)$ and turbulent kinetic energy $(k)$ with the experimental results obtained by Mengy and Hibi (1998) at the vertical axes located at the central plane of the domain according to the diagram shown in Fig. 3.

Table 2 shows the hit rates $(H R)$ for streamwise velocity $(U)$ and the turbulent kinetic energy $(k)$. These hit rates, evaluated at the vertical axes V1-V4 of Fig. 3 , are calculated according to Toja 3 Silva et al. (2015) and Santiago et al. (2007). Additionally, Table 2 shows the simulation results obtained for the reattachment distance $\left(X_{R}\right)$. relative to the roof length, of the recirculation vortex on the building roof. The model used in the present investigation (modified Durbin) successfully passed the validation of $U$ with a hit rate $\left(H R_{U}\right)$ of $87.5 \%$ and for $k$ with $H R_{k}=75.0 \%$ on the building roof, and it exactly matches the same distance of reattachment of the flow on the roof $\left(X_{R}=0.52\right)$ obtained at the wind-tunnel experiment of Meng and Hibi (1998). Additionally, the results corresponding to both Standard $k-\varepsilon$ (SKE) and Murakami-Mochida-Kondo (MMK) (Tsuchiya er al., 1997) turbulence models are presented in Table 2. The SKE model is shown as a reference, because it is not

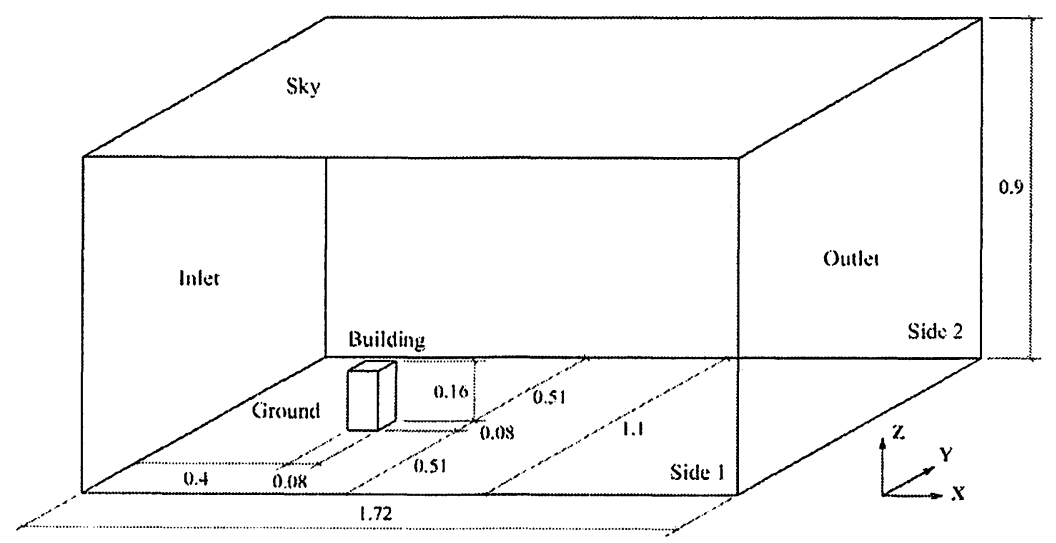

Fig. 1. Diagram of the wind-tunnel building for the validation of the mean flow. All dimensions are in meters (Toja-Silva (t al., 2015). 
a

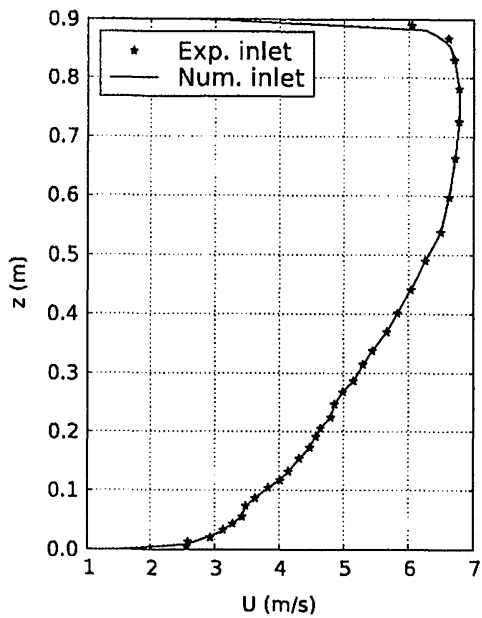

b

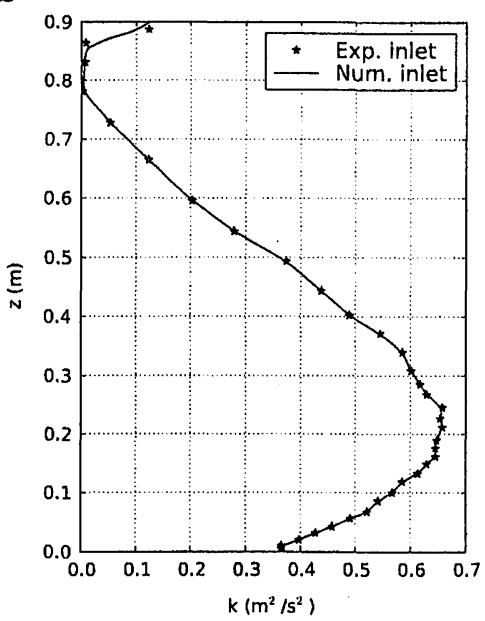

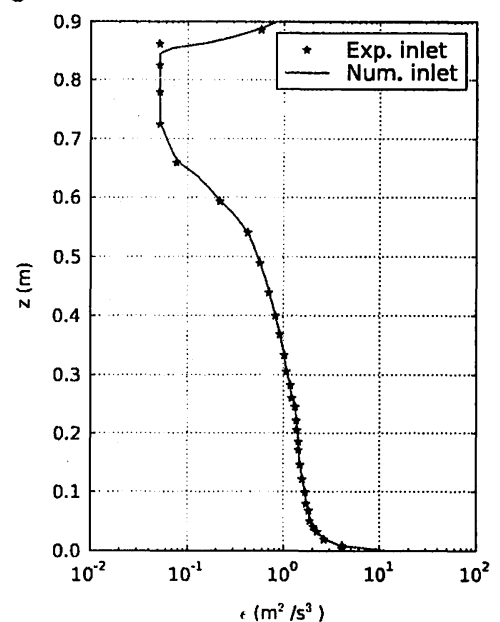

Fig. 2. Inlet profiles: mean streamwise velocity (a), turbulent kinetic energy (b) and turbulent dissipation (c). The points represent the inlet profiles used at the experiment

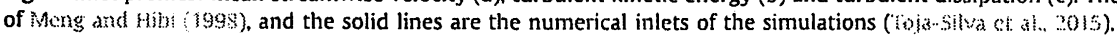

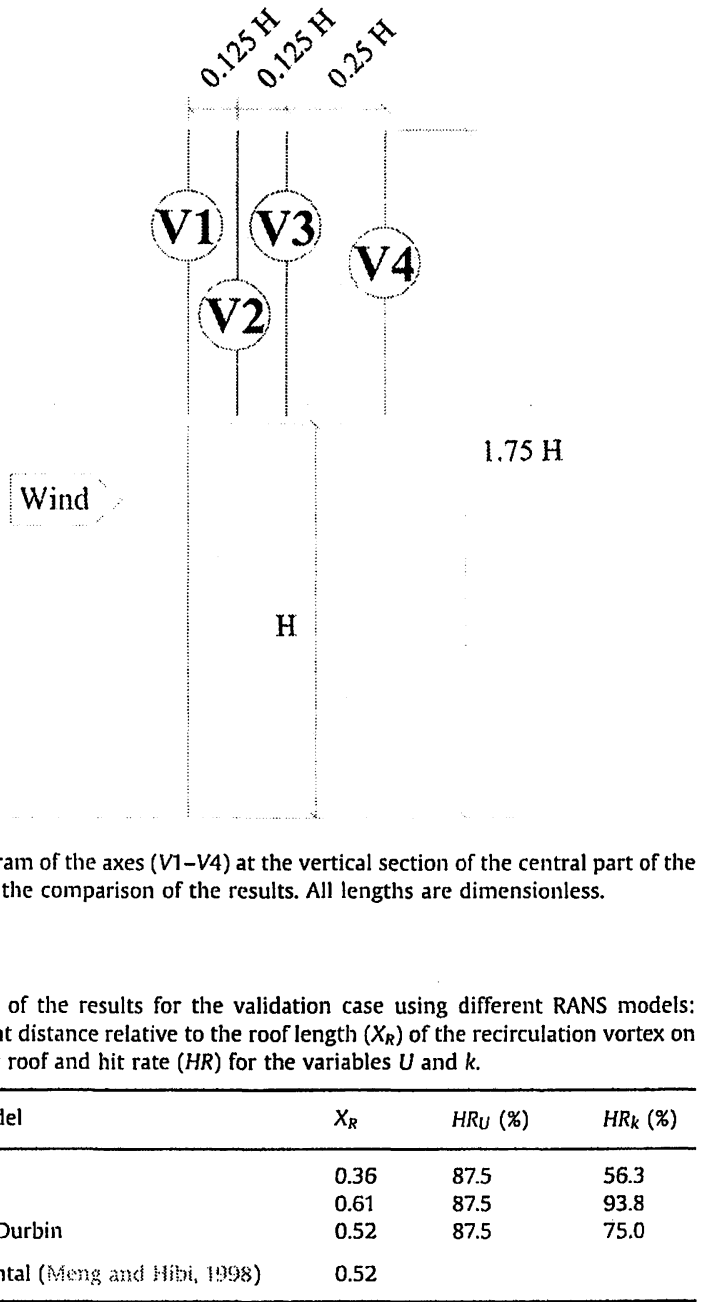

Fig. 3. Diagram of the axes (V1-V4) at the vertical section of the central part of the domain, for the comparison of the results. All lengths are dimensionless.

Table 2

Comparison of the results for the validation case using different RANS models: reattachment distance relative to the roof length $\left(X_{R}\right)$ of the recirculation vortex on the building roof and hit rate $(H R)$ for the variables $U$ and $k$.

\begin{tabular}{llll}
\hline RANS model & $X_{R}$ & $H R_{U}(\%)$ & $H R_{k}(\%)$ \\
\hline SKE & 0.36 & 87.5 & 56.3 \\
MMK & 0.61 & 87.5 & 93.8 \\
Modified Durbin & 0.52 & 87.5 & 75.0 \\
Experimental (Meng and Hibi, 1998) & 0.52 & & \\
\hline
\end{tabular}

successfully validated for $k$. Note that a turbulence model is considered successfully validated when $H R>66 \%$ (Toja-Silva at al., 2015; Santiago et al, 2007). The MMK turbulence model is shown because it obtains the highest hit rate values, although it overestimates $X_{R}$.

Fig. 4 shows the velocity profiles obtained at the vertical axes shown in Fig. 3 using SKE, MMK and the modified Durbin turbulence models, compared with the experimental data of Meng and Hibi (1998). Additionally, the profiles corresponding to the fullscale case (case-study building without solar panels) are also plotted. The full-scale case is included in this section in order to investigate possible issues related to the scaling of the problem, for a further comparison between the results obtained in wind-tunnel experiments with those obtained at full-scale cases. The agreement of the velocity profiles with the experimental results is reasonably good in all cases. The modified Durbin and MMK models show a better agreement. Even the full-scale case shows a good agreement. The inlet profiles in the real case are set according to Richards and Hoxey (1093) (explained below) and, thus, they are different from the inlet profiles used in the windtunnel experiment. On one hand, the reference velocity is the same in both cases $\left(U_{\text {ref }}=4.4 \mathrm{~m} / \mathrm{s}\right)$ but, on other hand, it causes that the Reynolds number be 3 orders of magnitude higher in the full-scale case $\left(R e=4.7 \times 10^{4}\right.$ at the wind tunnel and $\operatorname{Re}=1.2 \times 10^{7}$ at the real scale). This is the reason why the velocity profile far from the roof surface is different in both cases, although the results near the roof surface are in a reasonably good agreement. The Reynolds number increase causes a decrease of the boundary layer width in the full-scale case.

Fix. 5 shows the turbulent kinetic energy profiles obtained at the vertical axes shown in $\mathrm{Fig} .3$ using SKE, MMK and the modified Durbin turbulence models, compared with the experimental data of Meng and Hibi (1998). Additionally, the profiles corresponding to the full-scale case are also plotted. The agreement of the $k$ profiles with the experimental results is reasonably good in all cases, although $k$ is clearly overestimated close to the upstream edge of the roof. The modified Durbin and MMK models show a better agreement. Even the full-scale case shows a good agreement. As mentioned above, the inlet profiles in the full-scale case are set according to Richards and Hoxey (1993) and, thus, they are different from the inlet profiles used in the wind-tunnel experiment. This is the reason why the $k$ profile far from the roof surface is different in both cases, although the results near the roof surface are in a reasonably good agreement. The Reynolds number increase causes a decrease of the boundary layer width in the fullscale case. 
a
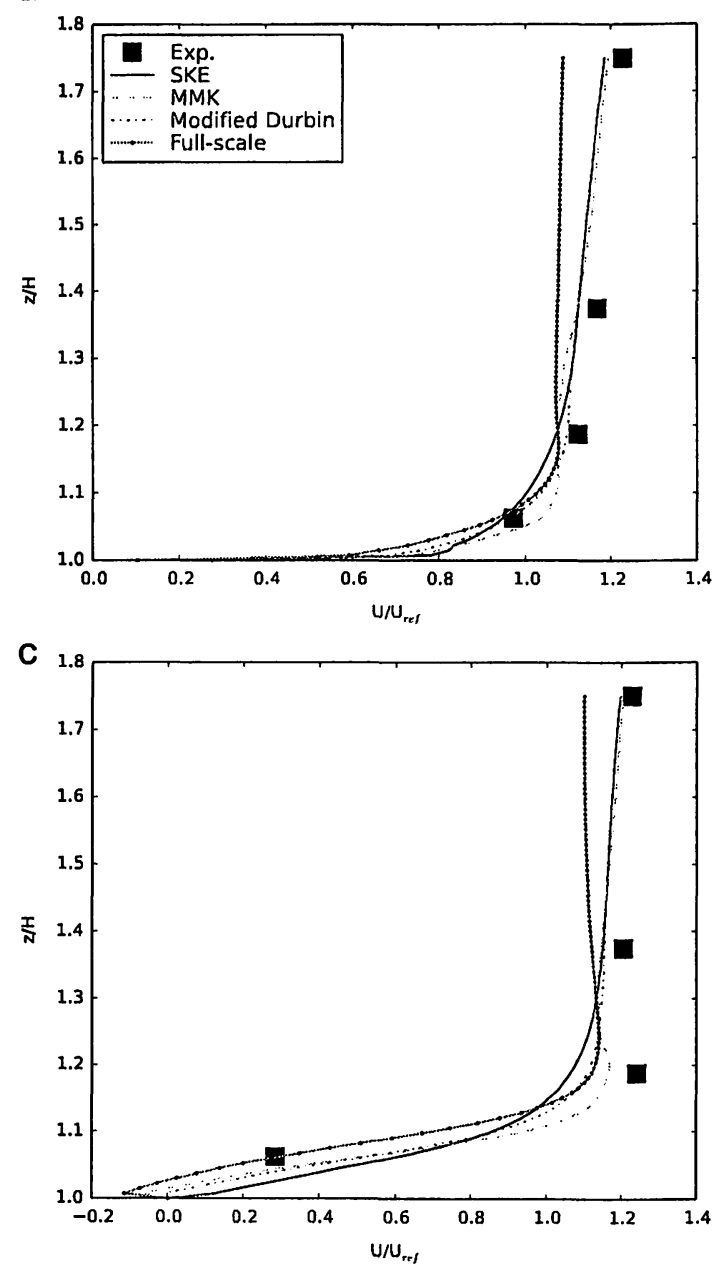

b

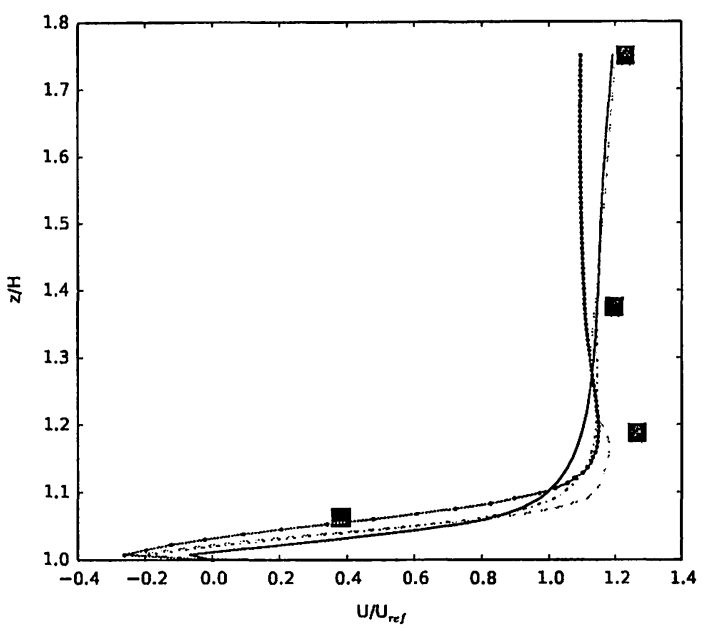

d

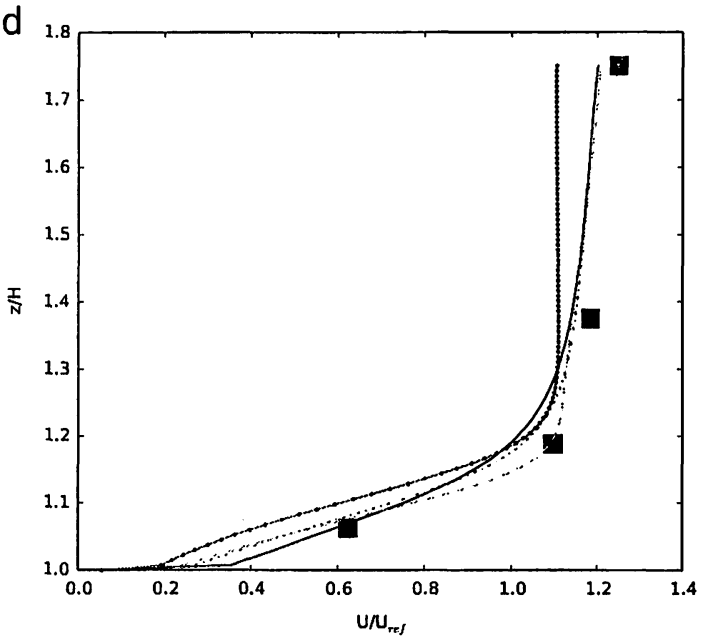

Fig. 4. Vertical profiles comparison for $U / U_{\text {ref }}$ for the full-scale empty roof case and using SKE, MMK and the modified Durbin for the wind-tunnel case for validation. The reference values are the reference velocity $U_{\text {ref }}=4.4 \mathrm{~m} / \mathrm{s}$ and the height of the building $H(0.16 \mathrm{~m}$ for the wind tunnel and $40 \mathrm{~m}$ for the full-scale case): (a) $V 1$, (b) $V 2$, (c) $V 3$, and (d) V4.

The results obtained using the MMK model are presented in this section to show that it is the turbulence model that reaches the best agreement with the experimental data. This model produces the highest hit rates (specially for $k$ ) but it underestimates the kinetic energy (see Fig. 5). Instead, the modified Durbin model is used in the present investigation (and it is recommended for the simulation of the wind flow around buildings) because it tends to slightly overestimate $k$ and, thus, it produces more conservative results. This is important in real facilities because real buildings have more roughness elements than in theoretical studies (antennas, ornamental elements, odd edges, birds, etc.). Additionally, it has been empirically found that the modified Durbin turbulence model produces more reliable results in more complex geometries (for example with solar panels)

In order to check the order of convergence of the solution obtained with the modified Durbin model, a grid dependency study is carried out testing 3 different meshes: coarse (1.7 M cells), medium-size ( $3.1 \mathrm{M}$ cells) and fine (9.8 $\mathrm{M}$ cells) meshes. The hit rate obtained for $U$ is the same in all cases, but the hit rates for $k$ are $68.8 \%, 75.0 \%$ and $81.3 \%$ for coarse, medium-size and fine meshes, respectively. To check the order of convergence of the numerical scheme, the grid convergence index (GCI) is calculated according to Roache (1998) by using the total number of cells and the hit rate of $k$. The observed convergence rate is $p=2.23$ and the grid convergence index is $G_{2} l_{21}=0.0577$ (5.77\%).

\subsection{Validation of the flow around a single array of solar panels}

In order to guarantee a rigorous result, an additional validation is carried out. A single infinite-span array of solar panels (flat plate) is validated according to the experiment of Fage and Johansen (1927). The size of the domain follows the specifications of Bosch and Rodi (1996) in order to minimise blockage issues. Fig. 6 shows a diagram of the geometry. The axis where the simulation velocities are compared with the experimental data is indicated as "AXIS" in the figure. The slip boundary condition is imposed at the top, bottom and two side walls, assuming them as far-field free stream-surfaces. A no-slip boundary condition is applied on the plate. A uniform velocity of $U_{\infty}=1 \mathrm{~m} \mathrm{~s}^{-1}$ and a uniform turbulent kinetic energy $k=0.002 \mathrm{~m}^{2} \mathrm{~s}^{-2}$ are set at the inlet. The unstructured mesh is constructed using the snappyHexMesh application of OpenFOAM (http:/openfoanwikinet/ index.php/SnappyHexMesh; https://sites.googlecom/site/snappywiki/snappyhexmesh/snappyhexmeshdict), which resulted in around $6.4 \mathrm{M}$ cells. The corresponding Reynolds number based on the plate length is $R e=7 \times 10^{4}$. 
a

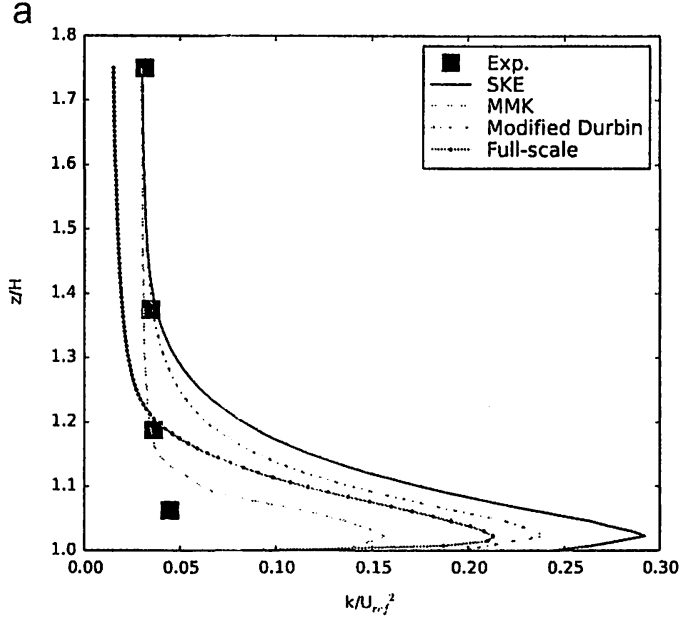

C

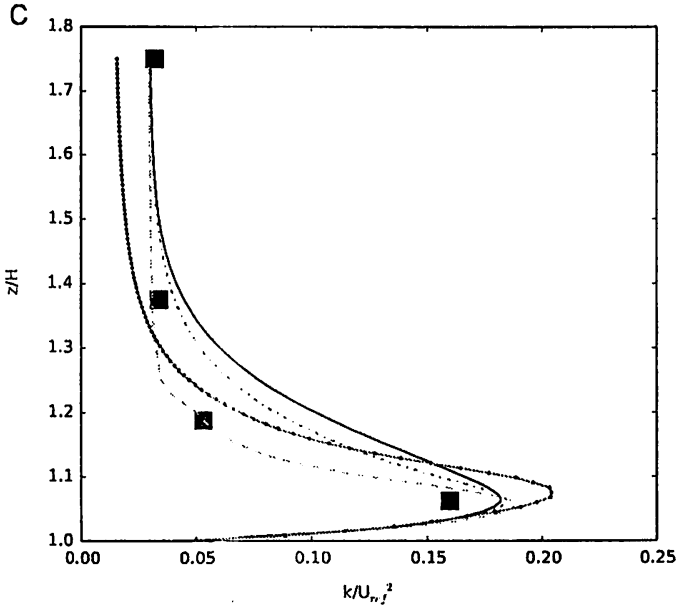

b

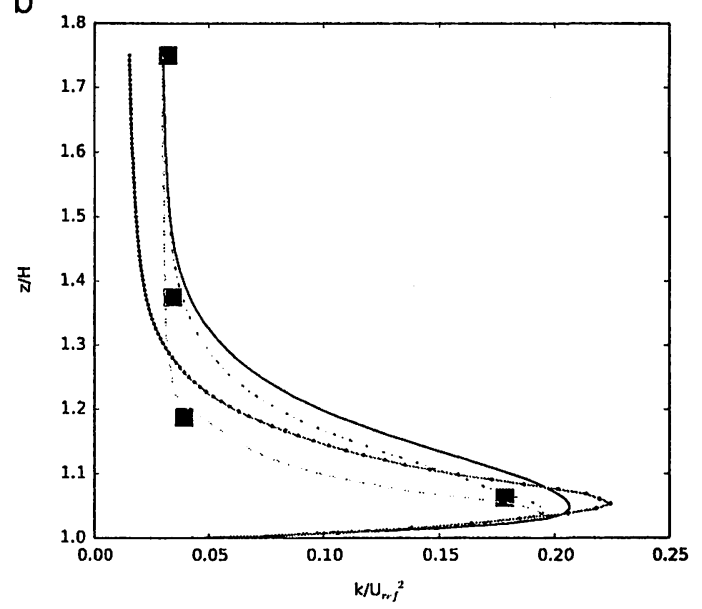

d

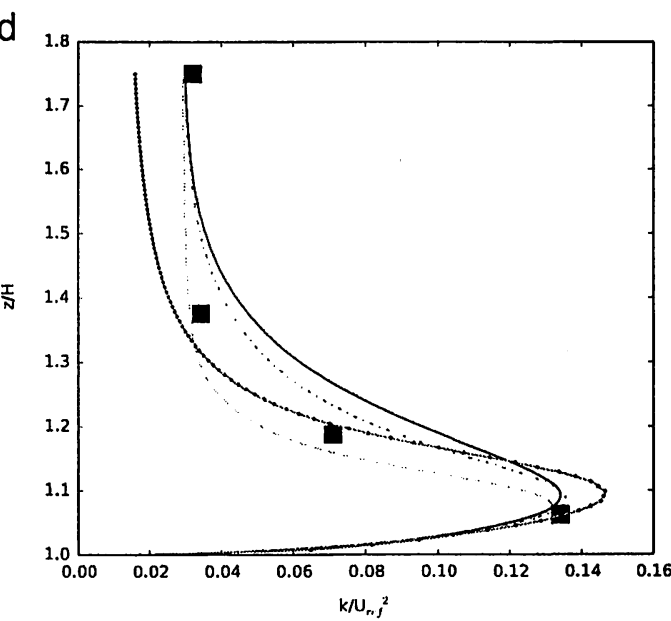

Fig. 5. Vertical profiles comparison for $k / U_{\text {ref }}^{2}$ for the full-scale empty roof case and using SKE, MMK and the modified Durbin for the wind-tunnel case for validation. The reference values are the reference velocity $U_{\text {ref }}=4.4 \mathrm{~m} / \mathrm{s}$ and the height of the building $H(0.16 \mathrm{~m}$ for the wind tunnel and $40 \mathrm{~m}$ for the full-scale case): (a) $V 1$, (b) $V 2$, (c) V3, and (d) V4.

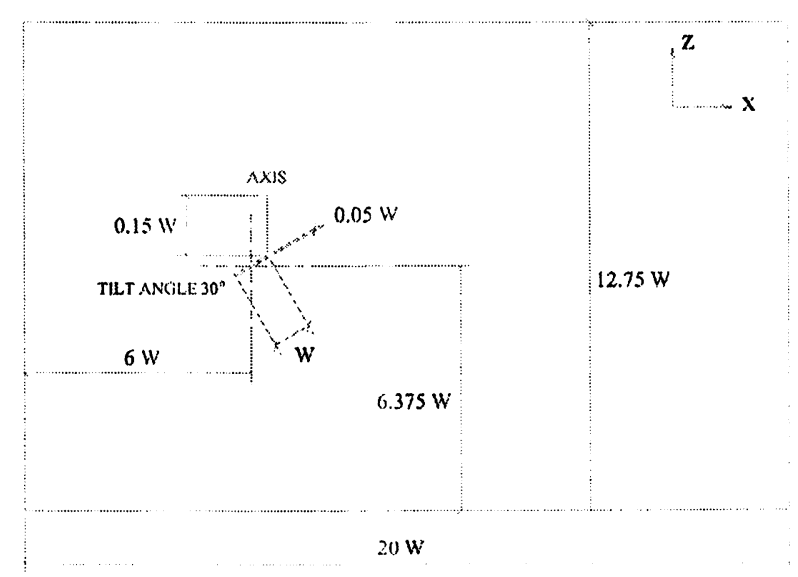

Fig. 6. Diagram of the validation of the infinite-span array of solar panels. The "AXIS" indicates the points where the data is compared for the validation. All values are dimensionless, expressed as multiples of the width of the plate $W=1 \mathrm{~m}$.

Fig. 7a shows a comparison between numerical and experimental results for $U$ at the vertical axis shown in Fig. 6. A hit rate of $H R_{U}=90.9 \%$ is reached. This hit rate indicates a very good agreement between the present simulation and the experimental results, specially near the solar array. Since the hit rate is higher than $66 \%$, the validation can be considered successful (Santiago et al, 2007).

Fig. $7 \mathrm{~b}$ shows the distribution of the mean pressure coefficient $C_{p}=2\left(P-P_{\infty}\right) /\left(\rho U_{\infty}^{2}\right)$ along the flat plate surface. The symbol $P_{\infty}$ means the free-stream pressure, $U_{\infty}$ is the free-stream velocity (or reference velocity) and $\rho$ is the density. A hit rate of $H R_{C_{p}}=70.4 \%$ is reached. This hit rate indicates a reasonably good agreement between the present simulation and the experimental results. This agreement is very good at the windward face of the solar array, but it is worse at the leeward face due to, on one hand, the well known difficulty for the RANS models to accurately reproduce the recirculation of the flow behind a sharp body (Toja-Silva et al., 2015; Tominaga et al. 2008) and, on the other hand, to the actual edge shape of the solar array at the experiment of Fage and Johansen (1927) (notice that it is a pioneer experiment from the year 1927). In any case, since the hit rate is higher than $66 \%$, the validation can also be considered successful for $C_{p}$ (Santiago et al.. 2007).

\section{Description of the test cases and simulation details}

The influence of roof-mounted solar panels on the wind energy potential is analysed by comparing both velocity and turbulent 
a

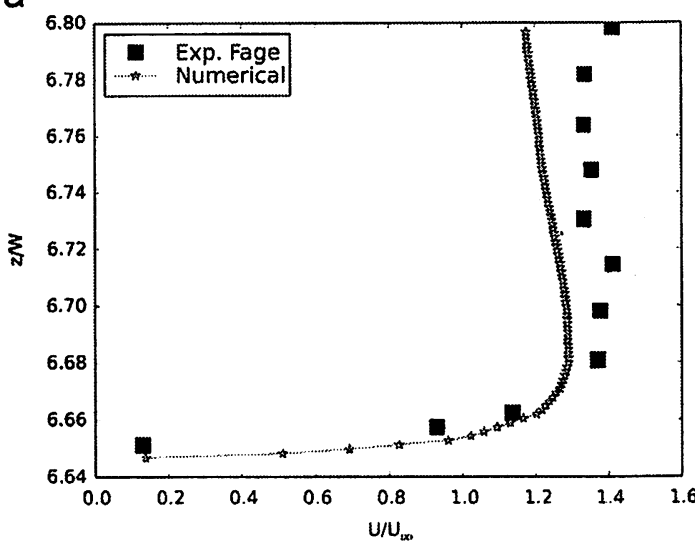

b

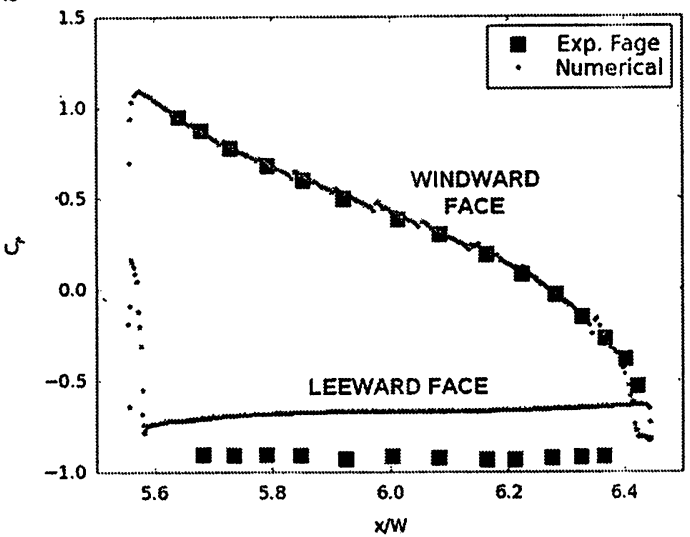

Fig. 7. Comparison between numerical and experimental values for validation using the experimental data of Fage and Johansen (1927). All values are dimensionless: distances with respect to the infinite array width $W$ and velocity with respect to the free-stream velocity $U_{\infty}$ (inlet velocity): (a) $U / U_{\infty}$ vs. $z / W$ at "AXIS" and (b) $C_{p}$ vs. $x / W$ at the flat plate surface.

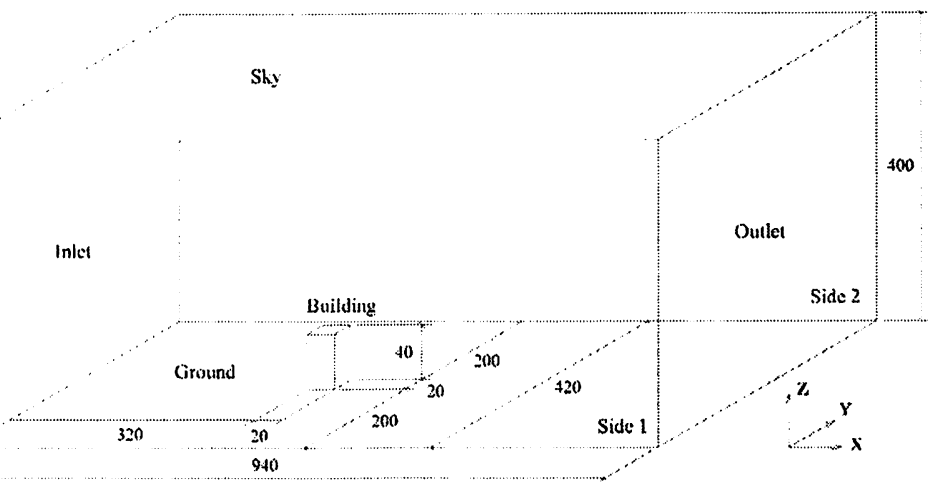

Fig. 8. Diagram of the computational domain of the full-scale building. All values are in meters.
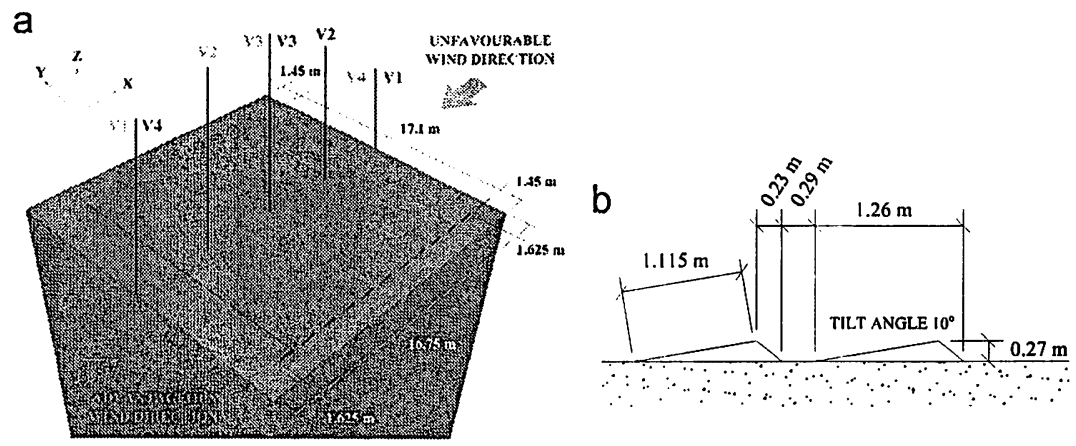

Fig. 9. Diagram of the geometry of the $41.75 \mathrm{~kW}$ photovoltaic facility with a tilt angle of $10^{\circ}$, at full scale: (a) 3D view. Advantageous (red) and unfavourable (blue) inciden wind directions and the corresponding vertical axes $V 1-V 4$ are shown and (b) solar panels' details. (For interpretation of the references to colour in this figure caption, the reader is referred to the web version of this paper.)

kinetic energy in a flat roof (without solar panels) with those in the same roof with solar panels installed. The base building is the benchmark case $A$ of the Architectural Institute of Japan (http:// wWw aij.or.jp/jpn/publish/cdguide/index...htm), analysed at fullscale. The height of the full-scale building is $40 \mathrm{~m}$ and the length of the sides is $20 \mathrm{~m}$. Fig. 8 shows the domain and dimensions of the full-scale building. The domain is set according to Best Practice Guidelines (Franke et al., 2007). According to Hall (1997), Cowan et al. (1997) and Scaperdas and Gilham (2004), for a single building a distance of $5 \mathrm{H}$ between the inflow boundary and the building is recommended if the approach flow profiles are well known. However, Bartzis et al. (2004) recommend $8 \mathrm{H}$ if the inlet flow profiles are not available in order to allow a realistic flow development. As in the present case the inlet wind profiles for the full-scale building are calculated according to Rithards and Hoxey (1993) (explained below), a constant value is set for $k$ at the whole height. Therefore, we use a distance of $8 \mathrm{H}$ between the inlet boundary and the building. The solar panels used in this study are the model Sunpower X21-345 (http://us.sunpowercom/sites/sunpower/files/media-library/data-sheets/ds-x21-series-335-34.5residential-solar-panels-datasheet.pdf). Two designs are considered: 


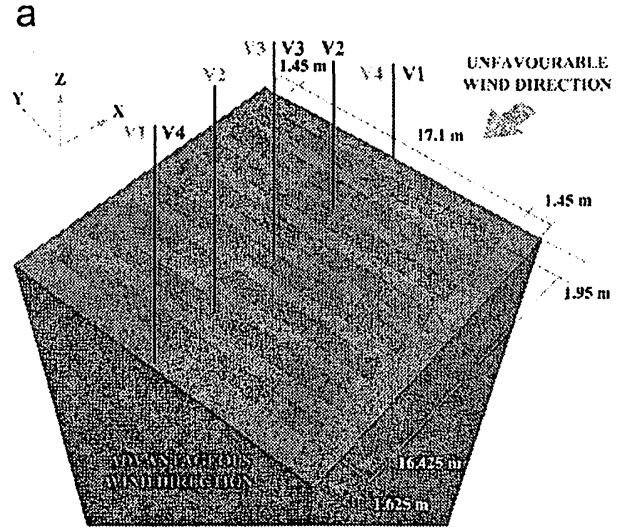

b

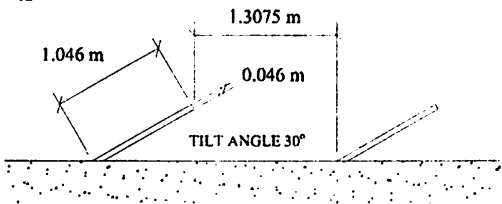

C

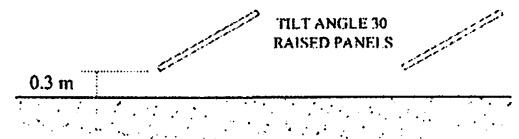

Fig. 10. Diagram of the geometry of the $30.36 \mathrm{~kW}$ photovoltaic facility with a tilt angle of $30^{\circ}$, at full scale: (a) $3 \mathrm{D}$ view. Advantageous (red) and unfavourable (blue) incident wind directions and the corresponding vertical axes $V 1-V 4$ are shown; (b) detailed panels close to the roof surface; and (c) detailed raised panels. (For interpretation of the references to colour in this figure caption, the reader is referred to the web version of this paper.)

(i) With a tilt angle of $10^{\circ}$ : In this case, the T-10 structure ( 37 ) is used. The total peak power of the photovoltaic plant obtained with this design is $41.75 \mathrm{~kW}$. Fig. 9 shows a detailed diagram of the geometry of this photovoltaic facility at full scale.

(ii) With a tilt angle of $30^{\circ}$ : As an example, this is the optimum tilt angle at the North-Mediterranean region. The separation between the solar panels arrays is calculated according to the Spanish normative (IDAE, 2011). The total peak power of the photovoltaic plant obtained with this design is $30.36 \mathrm{~kW}$. Fig. 10 shows a detailed diagram of the geometry of this photovoltaic facility. Additionally, the same facility was tested with the solar panels installed at $0.3 \mathrm{~m}$ height above the roof (Fig. 10c). This raised panels configuration is also tested because it is a common form of installation (http:/www.ecohisolar.couk/case-studies/ schuco-10-kwp), and differences in the behaviour of the flow are expected due to the gap between the solar arrays and the roof surface under the panels.

In both cases $\left(10^{\circ}\right.$ and $\left.30^{\circ}\right)$, the wind direction will be tested at the predictably most advantageous and unfavourable directions. This is, from left- and right-hand sides of the vertical section in Figs. 9b and 10b, c. Note that the names "advantageous" and "unfavourable" refer to the most/least aerodynamic positions according to the inlet wind direction, independent from its appropriateness for the application.

The simulations are performed in OpenFOAM (http:/www. openfoam.com). The same specifications explained in Section 3 are used for the full-scale building: inlet wind profiles, boundary conditions, and numerical schemes. The only exception is the top boundary condition (sky), where the slip boundary condition is imposed in the full-scale case. The inlet profiles used for the fullscale cases are calculated according to Richards and Hoxey (1993). using the equations

$U=\frac{U_{*}}{\kappa} \ln \left(\frac{z+z_{0}}{z_{0}}\right)$
$k=\frac{U_{*}^{2}}{\sqrt{C_{\mu}}}$

and

$\varepsilon=\frac{U_{*}^{3}}{\kappa\left(z+z_{0}\right)}$

where $z_{0}=0.01 \mathrm{~m}$, and $U_{\text {ref }}=4.4 \mathrm{~m} \mathrm{~s}^{-1}$ and $z_{\text {ref }}=40 \mathrm{~m}$ are considered as reference values in order to calculate $U_{*}$ by using Eq. (12). The turbulence model used is the modification of the Durbin $k-\varepsilon$ (Durbin. 1996) proposed in Toja-Silva et al. (2015), and the coefficients used are those proposed by Crespo et al. (1985) (explained in Section 3).

Regarding the mesh, a background mesh is constructed using the structured blockMesh application with a grading of 4 in the vertical direction. The building geometry (with the solar panels included), previously designed with a CAD tool and saved in STL format, is embedded into the background mesh using the snappyHexMesh application of OpenFOAM (http://openfoamwikinet) index.php/SnappyHexMesh; hrps//sites.google,com/site/snappywiki/snappyhexmesh/snappyhexmeshicic). This allows us to deal with any building shape. The mesh around the building is refined and adapted to its shape. Refinement is applied around the building surfaces. The refinement distance around the building surfaces is $80 \mathrm{~m}$. Fig. 11 shows the final meshes obtained for the empty roof and for the roof with solar panels with tilt angles of $10^{\circ}$ and $30^{\circ}$ (close and raised from the roof), respectively.

\section{Results and discussion}

In what follows, the simulation results for the 4 cases $\left(10^{\circ}, 30^{\circ}\right.$ close and raised and empty roof) are presented, and the influence of the presence of the roof-mounted solar panels on the wind flow is discussed. Additionally, the characteristics of the wind flow in all cases are analysed and compared, bringing an assessment of the possibility of the wind energy exploitation and identifying the 
a

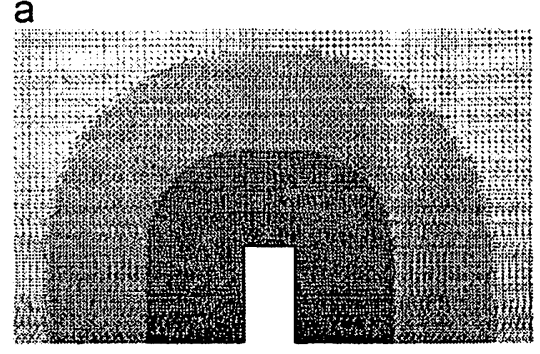

C

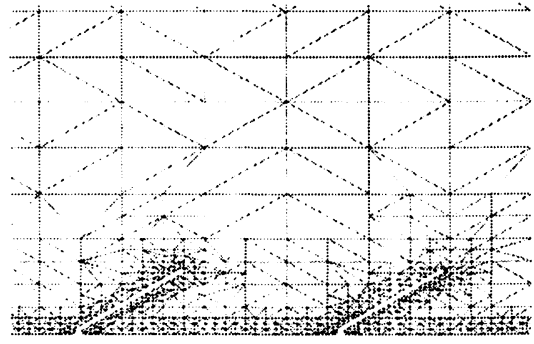

b

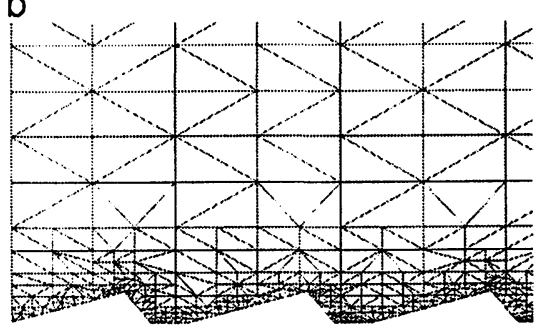

d

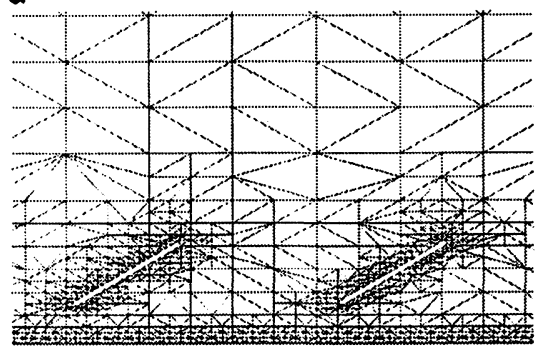

Fig. 11. Vertical section of the refined meshes obtained using snappyHexMesh: (a) general view mesh empty roof, $6.7 \mathrm{M}$ cells; (b) details of $10^{\circ}$ inclined solar panels, mesh with $6.9 \mathrm{M}$ cells; (c) details of $30^{\circ}$ solar panels, mesh with $7.1 \mathrm{M}$ cells; and (d) details of $30^{\circ}$ raised solar panels, mesh with $7.1 \mathrm{M}$ cells.

most appropriate kind of wind turbine for different parts of the roof. The analysis of the results can focus on either quantitative or qualitative aspects. Quantitative aspects focus on an accurate study of the data at the vertical axes shown in Fig. 3, and qualitative aspects focus on the behaviour of the wind flow on the roof (recirculation, wind direction, etc.).

The quantitative analysis is carried out by comparing $U$ and $k$ between the 4 cases (including most advantageous and

b
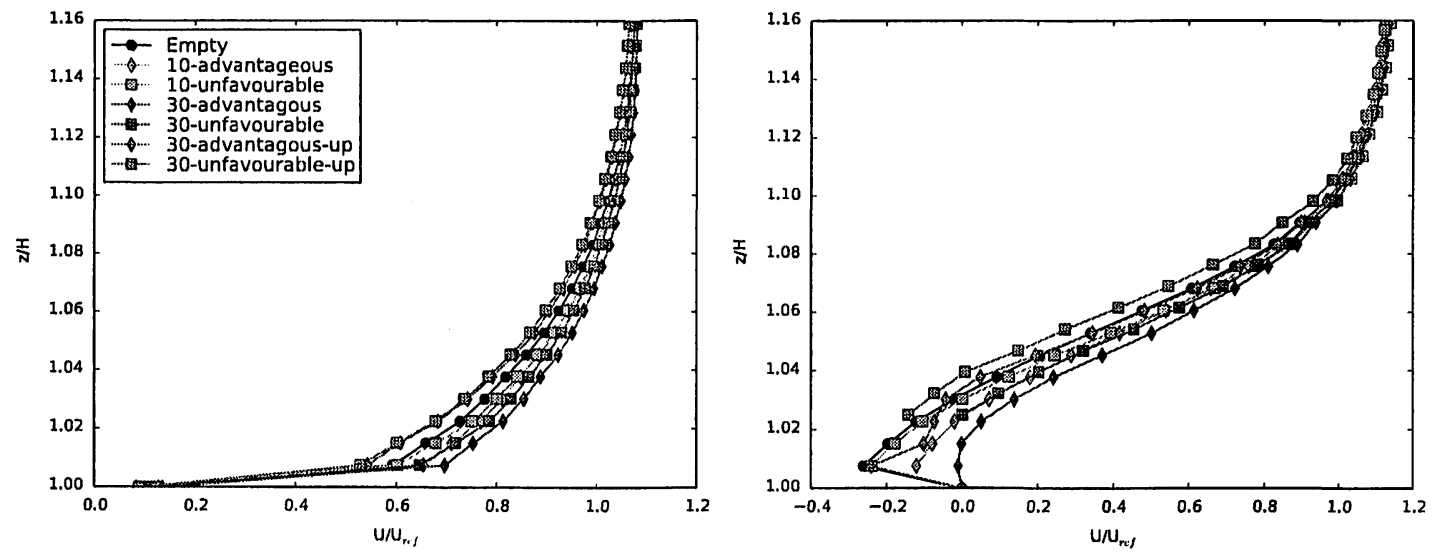

d

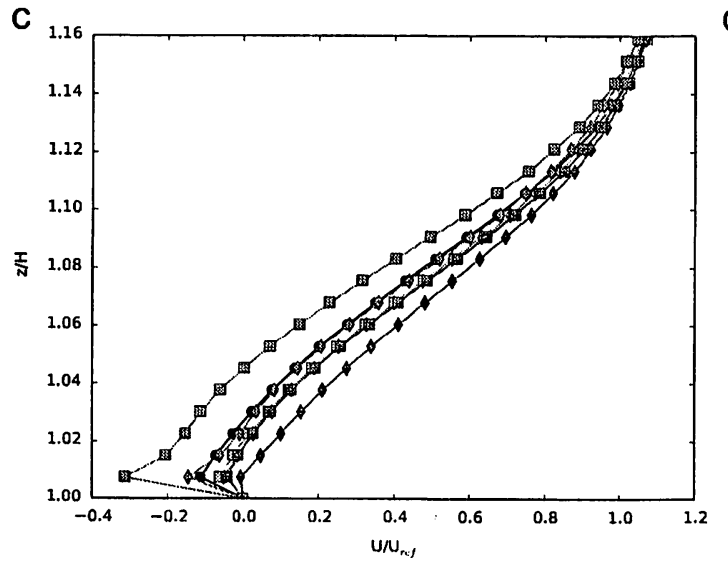

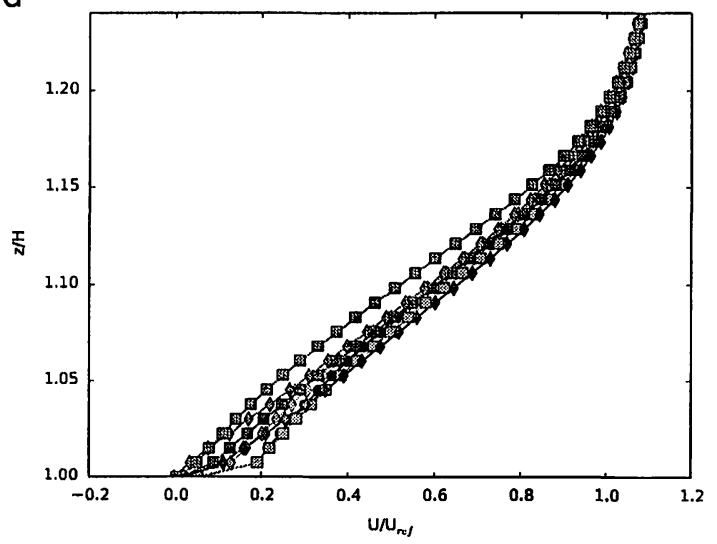

Fig. 12. Comparison of the velocity at the vertical section at the centre of the domain, for the full-scale model: (a) V1, (b) V2, (c) V3, and (d) V4. 
unfavourable situations) at the vertical axes located at the central plane of the domain according to the diagram shown in Fig. 3. For the analysis below, note that the height of the solar panels for the full-scale model is $0.27 \mathrm{~m}, 0.52 \mathrm{~m}$ and $0.82 \mathrm{~m}(z / H=0.007, z)$ $H=0.013$ and $z / H=0.02$ ) for $10^{\circ}$ and $30^{\circ}$ close and raised from the roof, respectively.

Fig. 12 shows the comparison of vertical profiles of the velocity at the different roof positions described in Fig. 3. It is observed that, in general, the raised panels tend to reduce the velocity and the rest of the cases, particularly $30^{\circ}$, tend to increase it. At $V 1, U$ decreases by $10 \%$ for the raised panels, and increases by $10 \%$ for $10^{\circ}$ in advantageous position and $30^{\circ}$ in unfavourable position and by $19 \%$ for the $30^{\circ}$ in advantageous position, at $z / H<0.18$. The major difference is just above the arrays $(z / H=0.007)$ in all cases. At $V 2$, the $U$ profile for the raised panels in advantageous position is similar to the profile of the empty roof. At $z / H<0.13, U$ decreases for the raised panels in unfavourable position and slightly increases in all the other cases. The highest increase is noticed for $30^{\circ}$ in advantageous position. At $V 3$, the $U$ profile of the raised panels in advantageous position follows rather the same values than for the empty roof, $U$ is drastically reduced until a $174 \%$ for the raised panels in unfavourable position at $z / H<0.18$, due to a massive recirculation of the flow, and is increased until a $97 \%$ at $z / H<0.15$ for $30^{\circ}$ in advantageous position. It slightly increases for the rest of the cases. At $V 4, U$ is reduced for the raised panels in unfavourable position until a $36 \%$ at $z / H<0.23$ and shows a slight deviation at the rest of the cases.

Fig. 13 shows the comparison of vertical profiles of the turbulence kinetic energy at the different roof positions described in Fig. 3. Surprisingly, the turbulent kinetic energy decreases due to the presence of the solar panels and the decrease is, in general, more pronounced for higher tilt angles, and even higher if the solar panels are raised from the roof. This result is surprising since previous authors (Kopp et al., 2012) assumed that the turbulence might increase due to the presence of obstacles on the roof, including solar panels. However, our result is validated with the experiment of Pratt and Kopp (2013), who found a decrease of the Reynolds Stresses, agreeing with the results of the present investigation. The decrease of the turbulent kinetic energy may be due to the damping effect of the recirculation vortices between the solar arrays (Fig. 14). In the case of the raised panels, the recirculation flow between the panels and the roof surface increases such damping effect. However, the raised panels, particularly in unfavourable position, show a particular behaviour at the centre and downstream, where $k$ increases at medium heights. This phenomenon (analysed below) is caused by the interaction between the vortices of neighbouring solar arrays. In what follows, the comparison rates are taken at the highest value of $k$ for the empty roof (peak value). At $V 1, k$ is reduced for the raised panels up to a maximum rate of $5 \%$ for the advantageous position. It increases for the rest of the cases, until a maximum rate of $5 \%$ for the $30^{\circ}$ in unfavourable position. At $V 2, k$ is reduced in all cases at $z / H=0.12$ until a maximum rate of $24 \%$ for the raised panels in advantageous position. At $V 3, k$ is reduced for the raised panels in unfavourable position at $z / H<0.11$ until $63 \%$. The value of $k$ clearly decreases at the rest of the cases at $z / H<0.13$ until a maximum rate of $19 \%$ for the case of the raised panels in advantageous position. The value of $k$ for the raised panels is slightly higher than for the empty roof at $0.13<z / H<0.28$. At $V 4, k$ is reduced for the raised panels in unfavourable position at $z / H<0.1$, for the raised panels and $10^{\circ}$ a

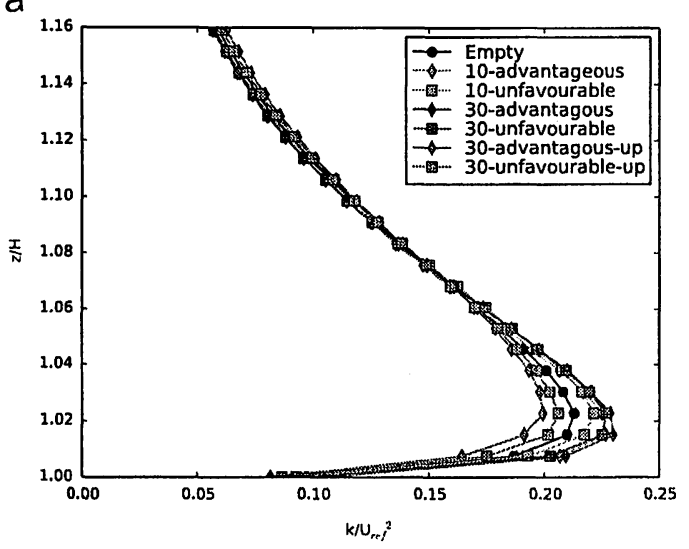

C

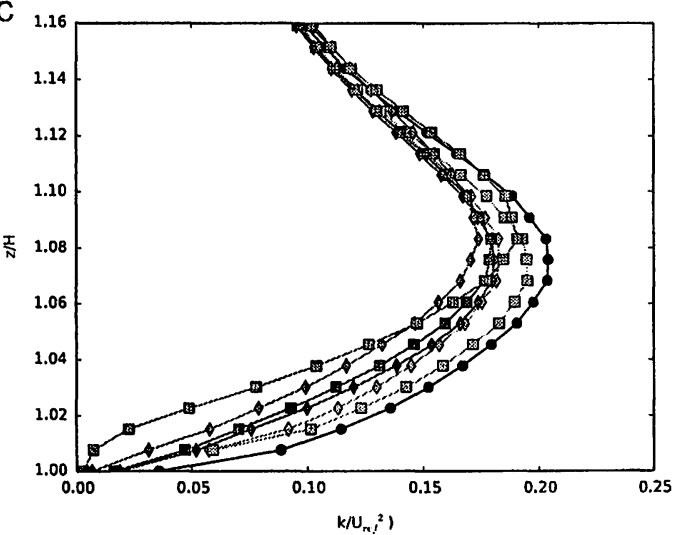

b

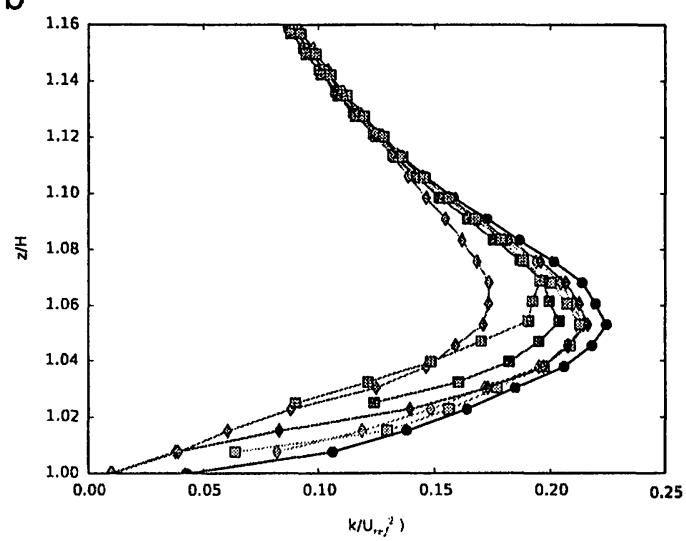

d

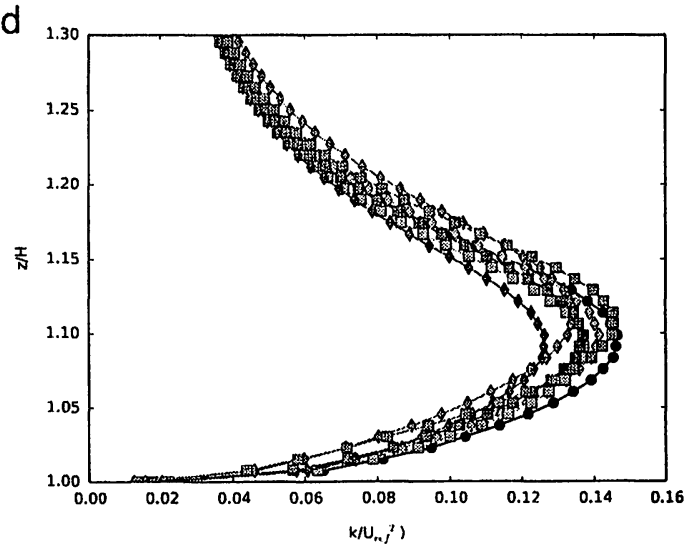

Fig. 13. Comparison of turbulent kinetic energy at the vertical section at the centre of the domain, for the full-scale model: (a) V1, (b) V2, (c) V3, and (d) V4. 
a

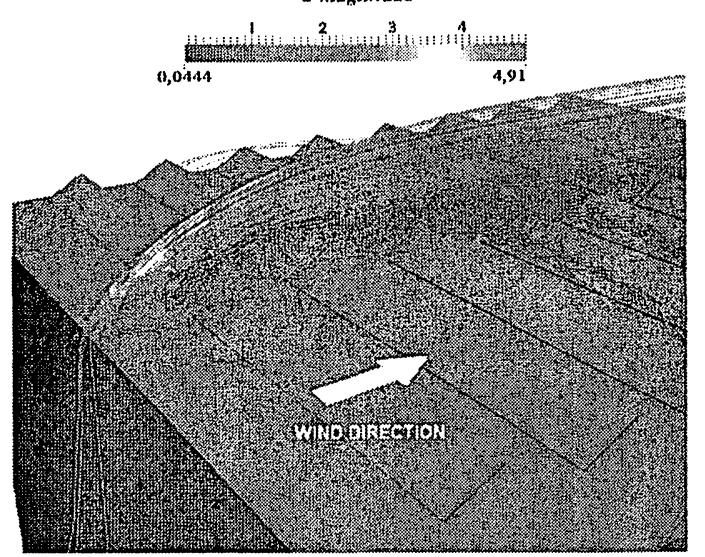

b

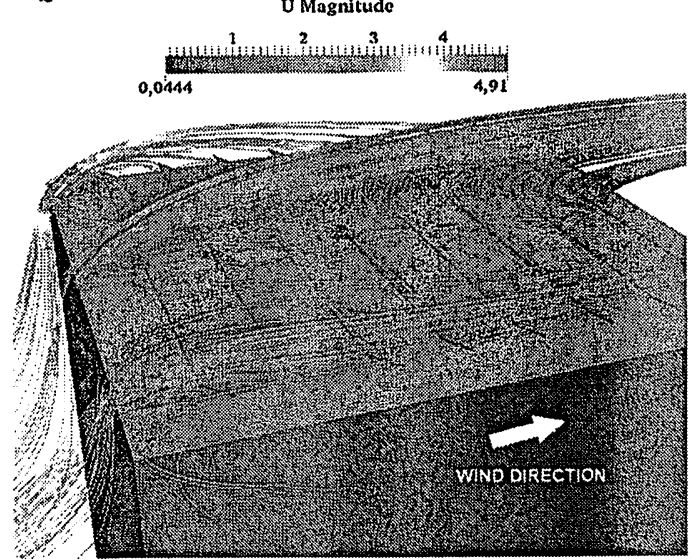

Fig. 14. Streamlines that show the recirculation vortices on the roof for the $30^{\circ}$ raised panels, at the full-scale model: (a) Advantageous position raised and (b) unfavourable position raised.

(both in advantageous position) at $z / H<0.14$, and at the rest of the cases at $z / H<0.28$, reaching a reduction rate of $14 \%$ for $30^{\circ}$ in advantageous position. Additionally, the raised panels in advantageous position show slightly higher values of $k$ at $0.14<z / H<0.35$, and also the raised panels in unfavourable position at $0.1<z / H<0.28$.

The most significant aspects for the qualitative analysis are the wind direction and the recirculations on the roof. Fig. 14 shows the recirculation vortices generated on the roof at the raised panels

a

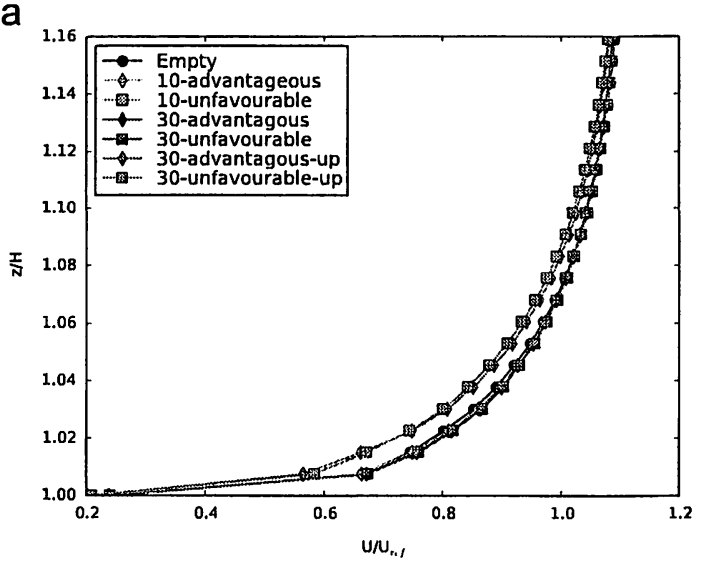

cases. In all other cases, recirculation vortices appear between all the arrays as in Fig. 14a. For the raised panels in unfavourable position, a massive recirculation that involves the whole roof length is observed (see Fig. 14b). This massive recirculation is not identified in the experiment of Pratt and Kopp (2013) due to a scaling issue, that is explained in detail below. In all the cases, a recirculation vortex appears between the upstream edge of the roof and the first array of solar panels.

b

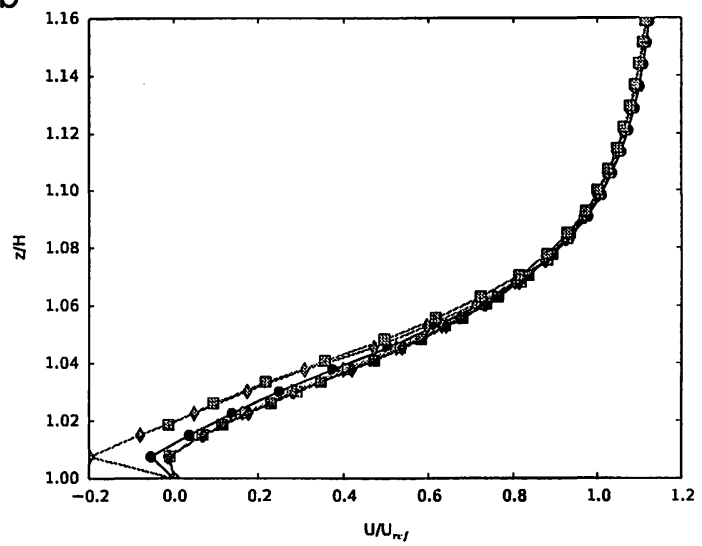

C

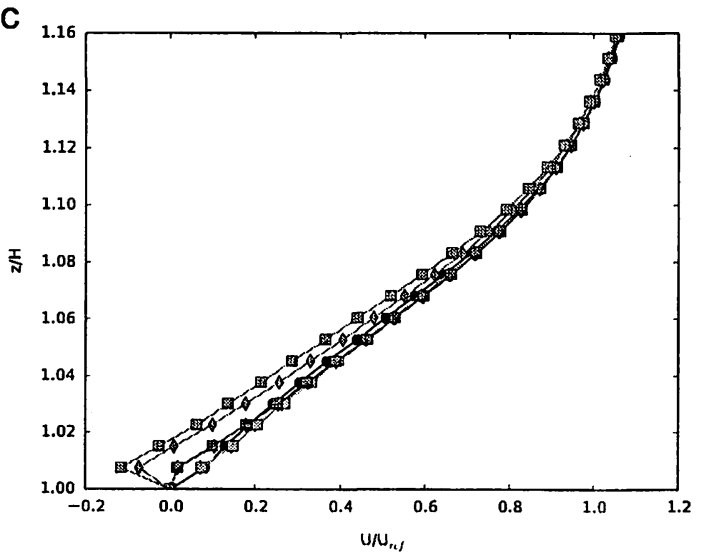

d

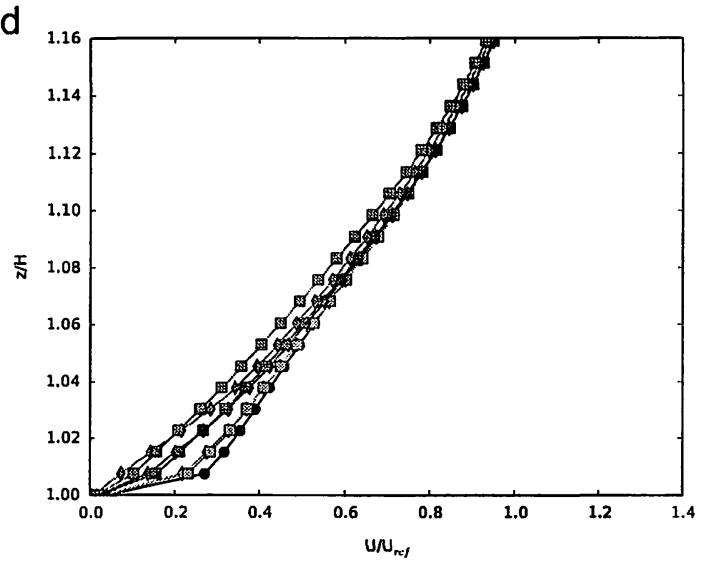

Fig. 15. Comparison of the velocity at the vertical section at the centre of the domain, for the reduced-scale model: (a) V1, (b) V2, (c) V3, and (d) V4. 
a

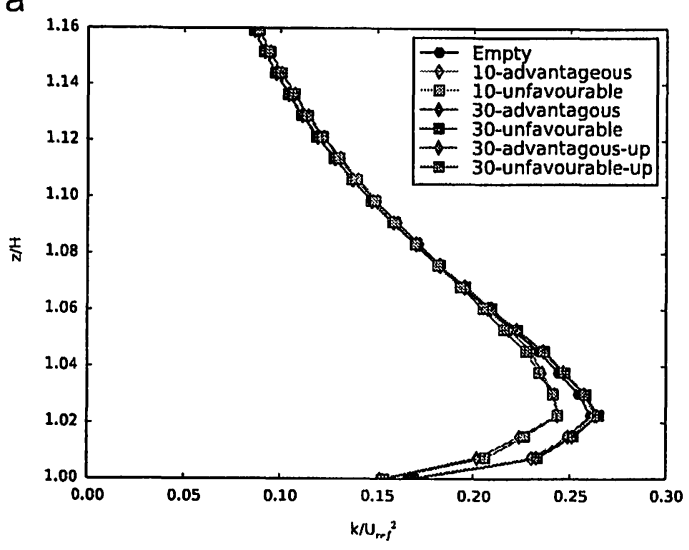

C

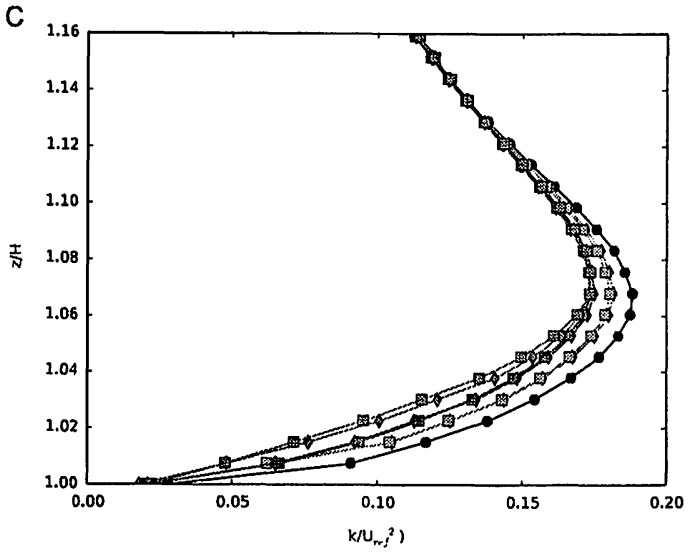

b

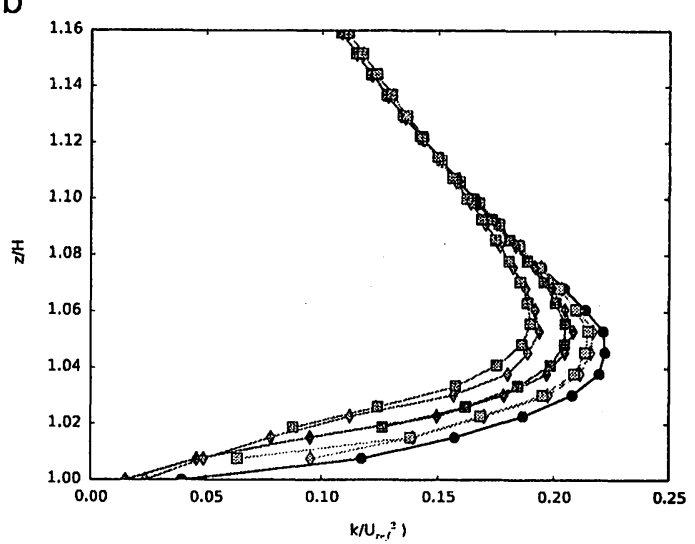

d

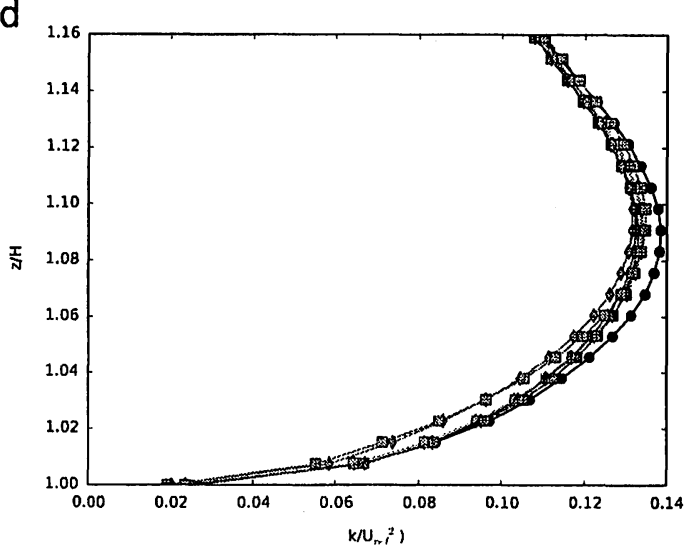

Fig. 16. Comparison of turbulent kinetic energy at the vertical section at the centre of the domain, for the reduced-scale model: (a) V1, (b) V2, (c) V3, and (d) V4.

\subsection{Scaling issues}

Possible scaling issues were briefly commented in previous sections. In order to verify these issues, we have simulated all the previous cases using a 1:250 reduced-scale model. Specifically, we have used the wind-tunnel building used for the validation of the main flow (Fig. 1). The main objective is to analyse the scaling issues involved in wind-tunnel experiments for the present application. The number of mesh cells used is $9.8 \mathrm{M}$ and $10.1 \mathrm{M}$ for the cases of close (both $10^{\circ}$ and $30^{\circ}$ ) and raised panels, respectively.

Figs. 15 and 16 show a comparison of vertical profiles of $U$ and $k$, respectively, at the different roof positions for all the situations described in Fig. 3. It is observed that, in general, the behaviour of both $U$ and $k$ for the reduced-scale model are in accordance with the behaviour for the full-scale model: the decrease of $k$ due to the presence of the solar panels, recirculation of the flow between each solar array and between the first array and the upstream edge. The exception is for the case of the raised panels in unfavourable position, that for the reduced-scale model behaves as in the rest of the cases, and the massive recirculation does not appear, as is shown in Figs. 15c and 17. Additionally, the results for the reduced-scale model show a more moderate behaviour than the full-scale models (the variations are lower and they take place at a lower height).

The behaviour of the flow at the reduced-scale model is in agreement with the experimental results obtained by Pratt and Kopp (2013). This is because the Reynolds number (based on the building height $H$ and the reference velocity $U_{\text {ref }}$ ) has the same
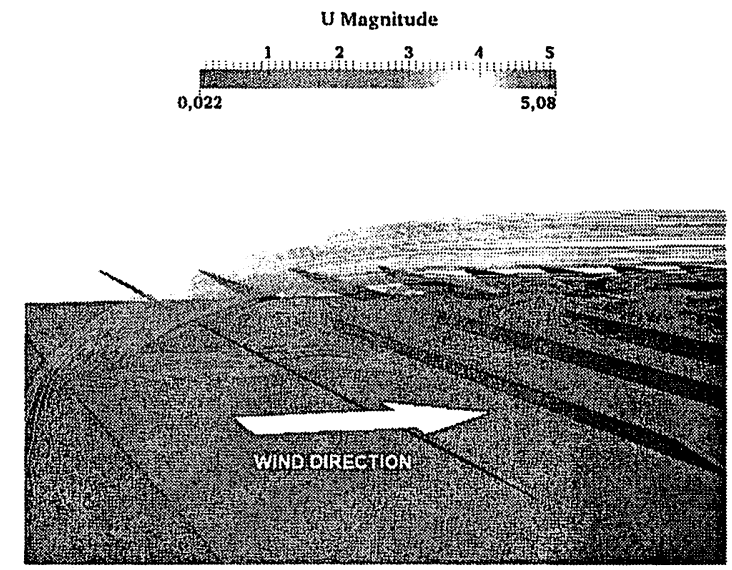

Fig. 17. Streamlines that show the recirculation vortices on the roof for raised panels in unfavourable position, at the reduced-scale model.

order of magnitude in both cases: $R e=4.7 \times 10^{4}$ at the reducedscale CFD simulations and $R e=1.9 \times 10^{5}$ at the wind-tunnel experiment of Pratt and Kopp (2013). However, for the full-scale building the Reynolds number is 2 orders of magnitude higher $\left(R e=1.2 \times 10^{7}\right)$. Prati and Kopp (2013) recognise that the Reynolds number of the wind-tunnel experiment is 2 orders of magnitude too low for being compared with real cases. For the case of raised panels in unfavourable position, the separation between the solar panels and the roof surface becomes more important with the 
increase of the Reynolds number. The interaction between the neighbouring vortices is powered by the negative-velocity flow between the solar panels and the roof. Since the flow is more turbulent in the full-scale building, the recirculation vortices between the solar arrays interact with the neighbouring ones, causing a massive recirculation of the flow that involves the whole roof length (see Fig. 14b). A solution verification (presented below) is carried out in order to determine if these effects are real.

Therefore, the necessity of further experiments with higher Reynolds numbers is confirmed in the present investigation, in order to experimentally validate the results obtained with the numerical simulations for full-scale buildings. These future experiments can be carried out by means of measurements on real-scale buildings, or in wind tunnels using water as a medium.

\subsection{Solution verification}

The independence of the final results from the grid resolution must be demonstrated. Since the cases where the recirculation vortices appear between each solar array were tested for different meshes and even for different scales, this solution verification is going to focus on the case of the raised panels in unfavourable position, where a massive recirculation of the flow is observed.

In order to check the independence of the results from the mesh resolution, the simulation case of the raised panels in unfavourable position is carried out by varying the mesh refinement on the roof (with the same background mesh), resulting in 3 different meshes: coarse ( $3.6 \mathrm{M}$ cells), medium-size ( $4.2 \mathrm{M}$ cells) and fine ( $7.1 \mathrm{M}$ cells) meshes.

a

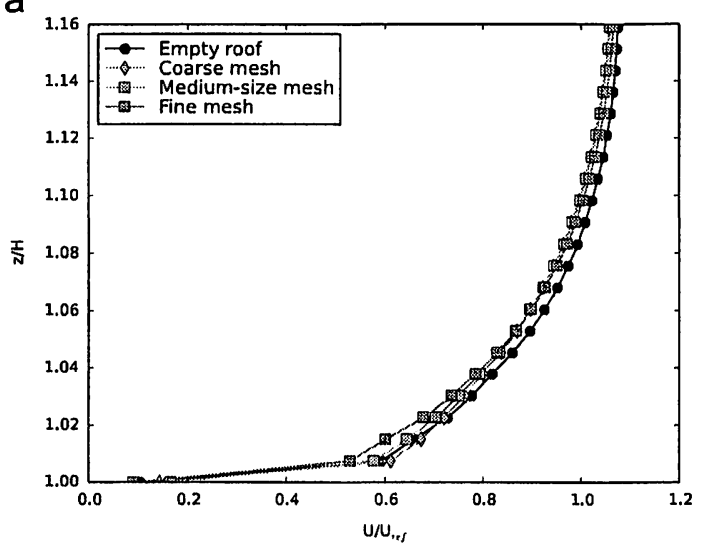

C

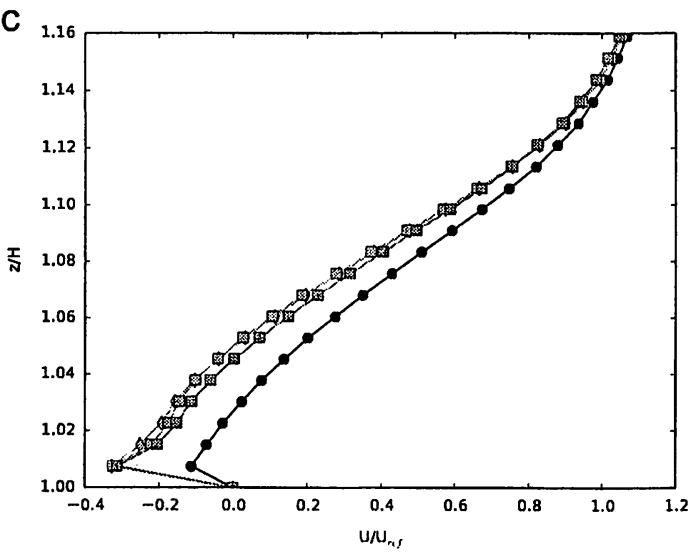

Fig. 18 shows the comparison of $U$ between the 3 mesh resolutions and the empty roof at the different positions described in Fig. 3. It is observed that the behaviour of $U$ is analogous for the 3 mesh resolutions, regarding the result on the empty roof. The most important point is that the massive recirculation of the flow is clearly confirmed for the 3 cases (see Fig. 18c).

Fig. 19 shows the comparison of $k$ between the 3 mesh resolutions and the empty roof at the different positions described in Fig. 3. It is observed that the behaviour of $k$ is also analogous for the 3 mesh resolutions, regarding the result on the empty roof, showing a clear decrease of $k$ in comparison with the empty roof. Therefore, the final solution can be considered verified.

\subsection{Wind energy exploitation and wind turbine positioning}

According to the European Wind Turbine Standards II (Pierik et al.. 1999), for a turbulence intensity higher than $T I=0.15$ the fatigue loads of VAWT have to be re-evaluated based on the real wind conditions. Therefore, $T I=0.15$ is used as a maximum admissible value for HAWT. Fig. 20 shows a plot of the vertical profiles of $T I$ up and downstream for the case of the raised panels (the most turbulent case) in comparison with the empty roof and with the wind-tunnel experimental results of heng and Hibi (1998). Five incident wind directions have been simulated in order to get a general conclusion about wind turbines positioning: $0^{\circ}$ (advantageous position), $45^{\circ}$ (oblique-advantageous), $90^{\circ}$ (lateral), $135^{\circ}$ (oblique-unfavourable) and $180^{\circ}$ (unfavourable position). From the incident wind directions tested, the advantageous position $\left(0^{\circ}\right)$ reaches the threshold $T I=0.15$ at a higher height both up

b

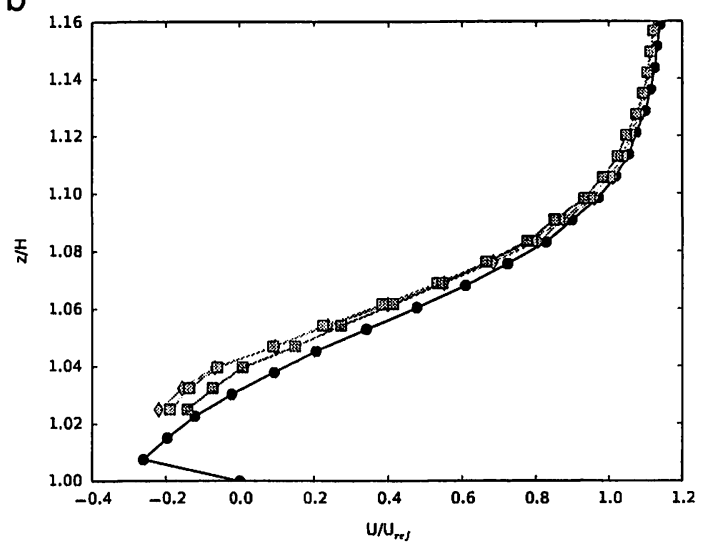

d

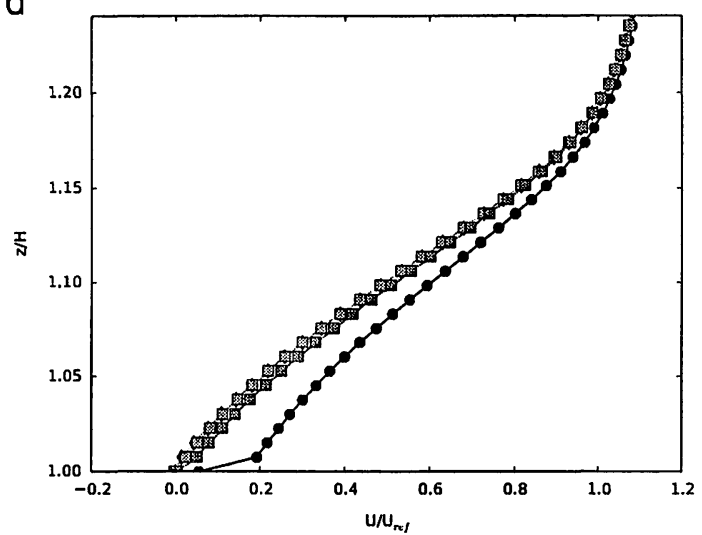

Fig. 18. Comparison of velocity at the vertical section at the centre of the domain using 3 different meshes. Case of raised panels in unfavourable position: (a) V1: (b) V2: (c) V3; and (d) V4. 
a
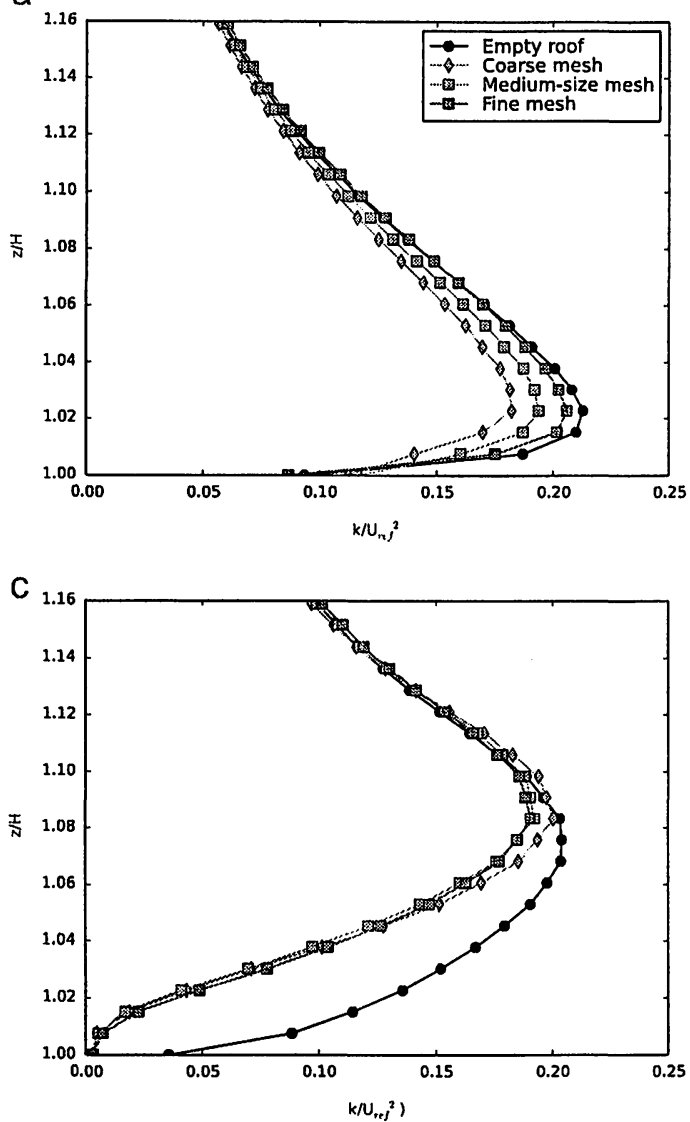

b

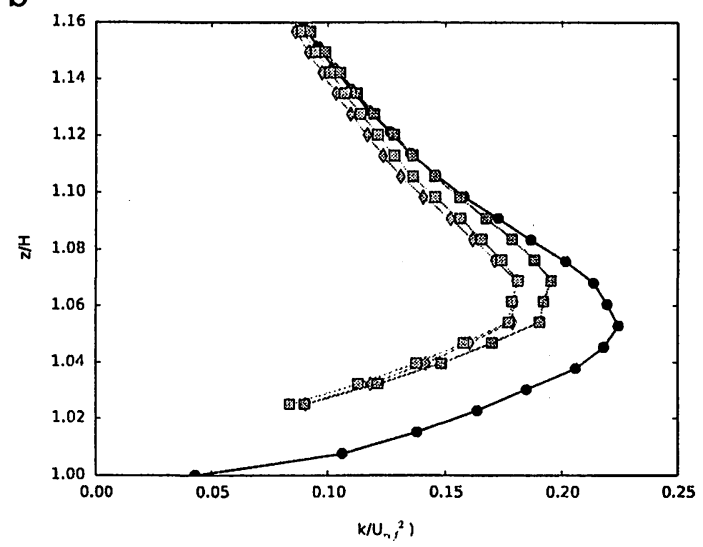

d

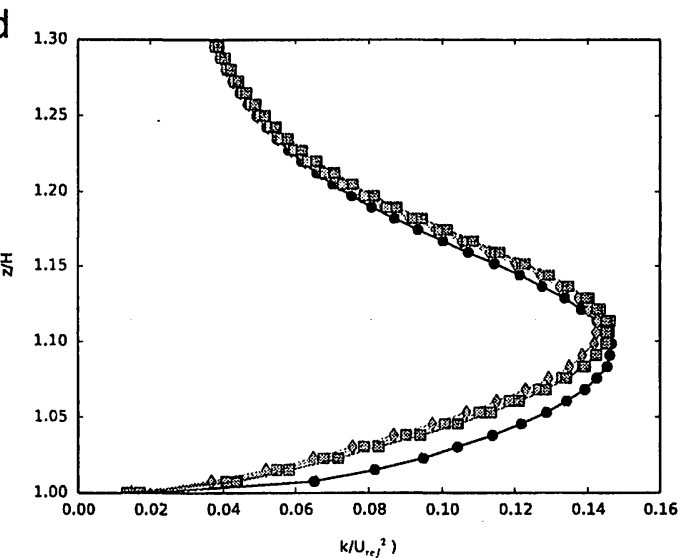

Fig. 19. Comparison of turbulence kinetic energy at the vertical section at the centre of the domain using 3 different meshes. Case of raised panels in unfavourable position: (a) $V 1$, (b) $V 2$, (c) $V 3$, and (d) $V 4$.

and downstream, at $z / H=0.2$ and $z / H=0.29$, respectively, where $H=40 \mathrm{~m}$ is the height of the building. The oblique incident directions $\left(45^{\circ}\right.$ and $\left.135^{\circ}\right)$ reach the threshold at the lower heights in all cases, at $z / H=0.11$ and $z / H=0.2$ up and downstream, respectively. For the rest of the incident wind directions tested, the threshold $T 7=0.15$ is reached at $z / H=0.19$ and $z / H=0.28$ up and downstream, respectively. This threshold is reached for the windtunnel experiment of Meng and Hibi (1998) at $z / H=0.19$ and $z /$ $H=0.31$ up and downstream, respectively. An additional scaling

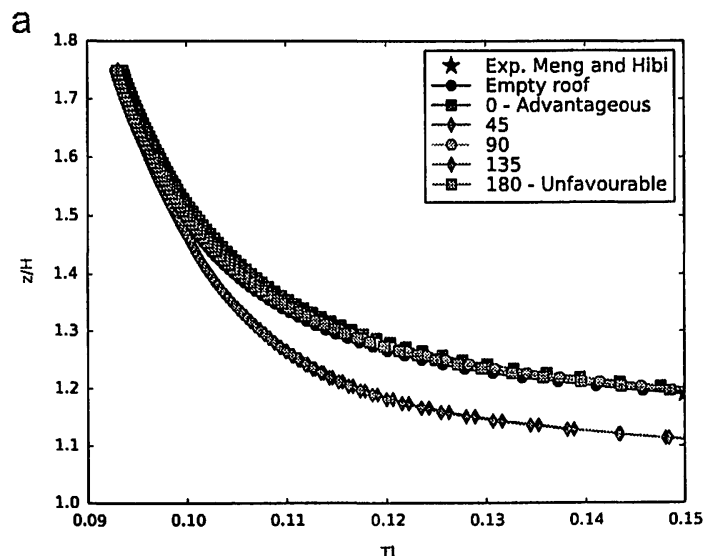

issue is reported here, because the threshold at the reduced-scale case is reached above than at the full-scale building. This is expected because the higher is the Reynolds number ( 2 orders of magnitude in this case) the thinner it is the boundary layer width.

Fig. 2la shows the turbulence intensity field around the raised panels in unfavourable position, and the isosurface corresponding to $T I=0.15$ throughout the roof. The grey line represents the limit $(T I=0.15)$ between the most adequate areas for a HAWT and a VAWT. The most adequate area to install a HAWT is above

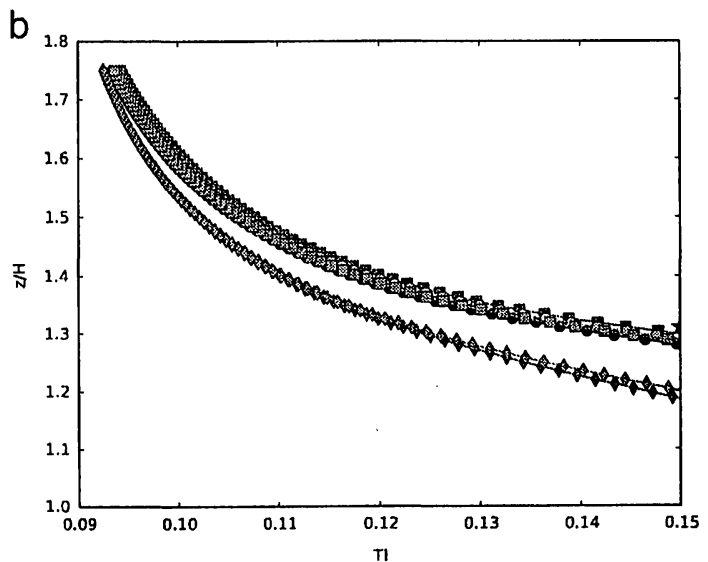

Fig. 20. Vertical profiles of turbulence intensity up and downstream of the roof considering different incident wind directions for the raised solar panels, until the threshold $T=0.15$ : (a) Upstream and (b) downstream. 
a

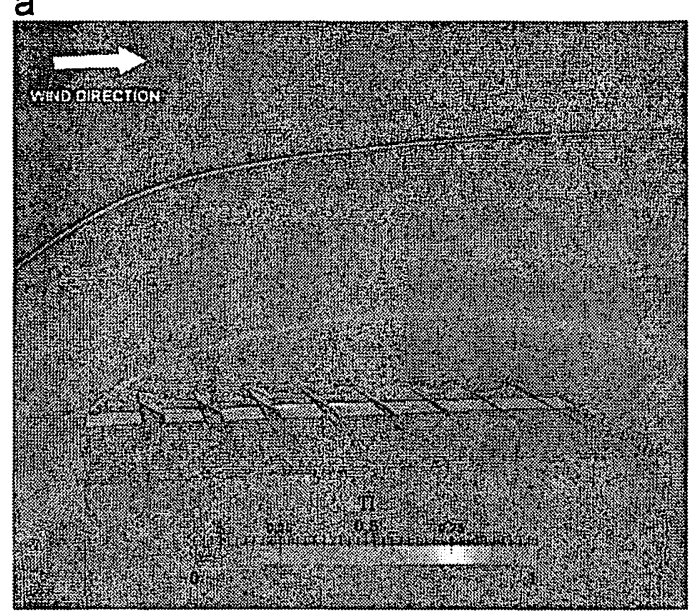

b

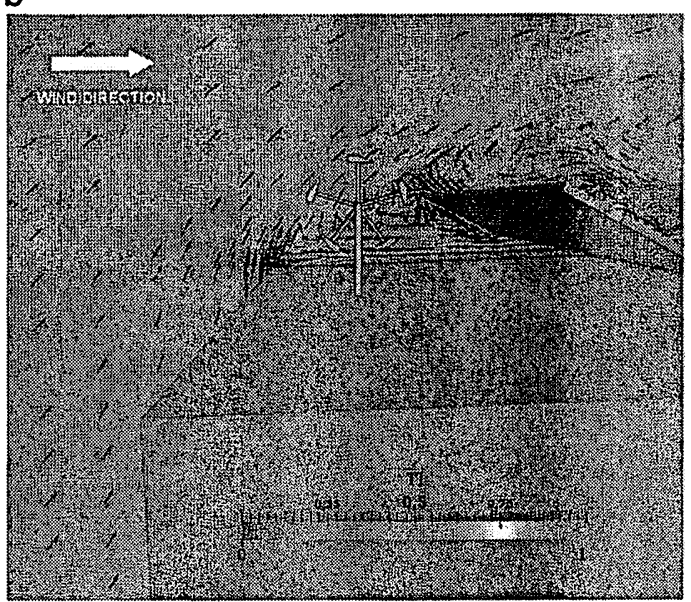

Fig. 21. Turbulence intensity field around the building and details of a VAWT in horizontal position upstream. The grey line represents the threshold $T I=0.15$ for the installation of HAWT (above) and VAWT (below), and the vectorial field is the velocity: (a) $\pi$ field around the building and (b) detailed VAWT in horizontal position upstream.

$T T=0.15$. Below this threshold a VAWT is more appropriate because it is more resistant to velocity fluctuations (Carpman. 2011). It is important to mention that such velocity fluctuations are lower due to the presence of the roof-mounted solar panels, and note that the presence of the solar panels does not affect significantly the wind flow below the threshold $T I=0.15$ in comparison with the empty roof. From the results above, a general rule for the wind turbines positioning on this kind of building roofs is proposed considering the most conservative values: HAWT must be positioned at $z / H>0.20$ upstream and $z / H>0.29$ downstream. Regardless of the incident wind direction, a HAWT can be placed at $z / H>0.29$ everywhere on the roof. Below these heights a VAWT must be considered.

Additionally, a VAWT can be placed in horizontal positions between the upstream edge of the roof and the first array of solar panels in order to take the most of the recirculation of the flow, as is shown in Fig. $21 \mathrm{~b}$. Due to the rotative character of the wind at this region, this wind turbine will not have opposite forces due to the wind (as in its conventional operation), which can significantly enhance the efficiency of the machine. One important factor to mention for this application is that for the advantageous directions the wind turbine may cause shadows over the solar panels and, therefore, the unfavourable directions are most adequate. Note that the names "advantageous" and "unfavourable" refer to the most/less aerodynamic positions according to the inlet wind although in this case, and also considering the results for the raised panels, the appropriateness has been found opposite to their respective names.

\section{Conclusions}

This work presents an investigation of the effects of roofmounted solar panels on the wind flow on building roofs, from the point of view of the wind energy exploitation, in order to analyse the compatibility of both systems. CFD simulations of the wind flow around an isolated building were performed with OpenFOAM using a modified Durbin RANS turbulence model. The turbulence model was validated twice: the main flow was validated using a wind-tunnel benchmark, and the flow around the solar panels by comparing CFD results with a wind-tunnel experiment of an infinite array. The wind flow on the empty roof is compared with roof-mounted solar panels cases. The solar panels are tested with tilt angles of $10^{\circ}$ and $30^{\circ}$, the most adequate inclination for solar panels in the Mediterranean region. For the tilt angle of $30^{\circ}$ the solar panels are tested both close and raised from the roof surface. Additionally, each inclination is simulated with 2 incident wind directions, advantageous and unfavourable, according to the aerodynamic position with respect to the incident wind. The analysis is carried out both quantitatively and qualitatively. The full-scale building results were compared with a reduced-scale model and scaling issues are reported. Additionally, the solution is verified in order to check the independence of the results from the mesh resolution. Finally, the wind flow on the roof is analysed and the most adequate wind turbine model for each roof region is suggested.

On the qualitative side, the recirculations on the roof were analysed and the most appropriate wind turbine model for each roof region was suggested. As it is expected, recirculation vortices appear between the solar-panels arrays. The first vortex (between the upstream edge and the first array) has the highest velocities. The installation of a VAWT in horizontal position inside this vortex shows a very interesting potential. A general value (the highest value obtained) for the installation of HAWT has been found at $z / H>0.29$, regardless of the incident wind direction The installation of a VAWT is recommended below this limit.

The quantitative analysis includes the comparison of vertical profiles of streamwise velocity and turbulent kinetic energy. No significant differences compared to the empty roof are found above the isoline of $T l=0.15$. Below the isoline $T l=0.15$ the most important differences appear for $k$, that significantly decreases due to the presence of the solar panels; such decrease is more pronounced for higher tilt angles. The decrease of the turbulent kinetic energy may be due to the damping effect of the recirculation vortices between the solar arrays. The results are in agreement with the experiments reported in the literature.

Scaling issues are reported. A massive recirculation takes place at the raised panels in unfavourable position due to the interaction of the neighbouring vortices between the arrays. This solution is verified in order to determine if it is a real effect. This massive recirculation is not identified at a reduced-scale model because of a Reynolds number decrease ( 2 orders of magnitude lower than full-scale building). These scaling issues show the necessity of further experimental studies considering full-scale conditions in order to confirm the simulation results obtained. These further experiments must involve higher Reynolds numbers, either by 
means of measurements on real (full-scale) buildings or in wind tunnels using water as a medium.

\section{Acknowledgements}

The authors acknowledge the computer time provided by the Facility for Large-scale COmputations in Wind Energy Research (FLOW) at the University of Oldenburg and the Euler cluster at the CIEMAT

\section{References}

Abohela. 1., Hamm, N. Dudek, S., 2013. Effect of roof shape, wind darection, building height and urban configuration on the energy yeld and positioning of rouf mouncel wind turbines. Renew. Energy 50, 11nk-1718.

Aly, A.M. Bitsuamiak, $C_{2}, 2013$. Aerodynamics of ground-mounted solar panels: test model sale eftecs. I. Wind Eng. Ind. Aerodvn. 123, 250-260.

Barzis, 1.C., Vachogiannis. D., Sfetso5. A, 2004. Thematic ared 5: best practice advice tor envirommental flows. ONET CFD Nerw. Newstert. 2, 34-39.

Blocken, B., Jakssen, W.D., van Hoof, T., 2012. CFD simulaton for pedestrian wixd comfore and wind safety in urban dreas: genem decision framework and case study for the Bindhoven University campus, Envirom. Nodel Soltw 30, $15-34$

Bincken, $B .2014,50$ years of computational wind engineering: past, present and future ?. Wias th Ind Aerodyn. 129, 69-102.

Bosch, C.. Redi. W. 1996. Simulation of yortex shedding past a square cylindex nedx a wall Int. I. Heat Fluid Flow 17, 267-275

Carpman. N., 2011. Turbulence Intensity in Complex Environments and its Influence on Small Wind Turbines (Ph.D. thesis). Uppsala University, Uppsala.

Cheng, X. lim, YS. Yce. E. Sinclair, R., 2003. A comparison of Large Eddy Simula. tions with a stondard $k-\varepsilon$ Reynolds-Averaged Nayier...stokes model for the predicton of a fully developed turbulent flow aver a marrix of cubes. J. Wind Eng. Int Aerodyn. 91. 1301-1328.

Chens, YM. Lu, YC, Hung, S.C., Cheng, C.S., 2007 . Multi-input inverter for gridconnected hybid PV/wind power system. IEEE Tans. Power Electron. 2 ? $1070-1076$.

Cowan, I.R., Castes, I.P. Robins, A.G. 1997. Numerical considerations for simulation of flow and dispersion around buildings. I. Wind Eng. Ind. Aerodyn. 67-68, $535-5.5$.

Craighead, G., 2009. High-rise building definition, development, and use. In: Highrise Cecurity and Fire Life Safety, 3rd edition. Butterworth-Heinemann, Boston (Chapter 1).

Crespo, A., Manuel, F., Moreno, D., Fraga, E., Hernandez, J., 1985. Numerical analysis of wind turbine wakes. In: Proceedings of Delphi Workshop on Wind Energy Applications, Delphi, Greece, pp. 15-25.

Durbin, $P A$. 1996. On the $k-\varepsilon$ stagnation point anomaly. Int. f. Heat Huid How 17 89.90.

Fage, A., Johansea, F.C. 1927. On the flow of air behind an inclined flat plate of infinite span. Proc. R. Soc. Lond. Ser. A 116. $17 \%$ j) $16 \%$

Franke, J., Hellsten, A., Schlünzen, H., Carissimo, B., 2007. Best Practice Guideline for the CFD Simulation of Flows in the Urban Environment. COST Action 732. COST Office, Brussels.

Gousseau, B., Blucken, B., wan Hejjst. G.J.F, 2013. Qudity assessment of large-Eddy Simulatin of wind flow around a high rise building: validation and solution verification. compuc. Fluids $79,120-133$.

Hall, R.C., 1997. Evaluation of Modelling Uncertainty. CFD Modelling of Near-field Atmospheric Dispersion. Project EMU Final Report, European Commission Directorate - General XII Science, Research and Development Contract EV5VCT94-0531, WS Atkins Consultants Ltd., Surrey.

Hong, C.-M., Chen, C.-H. 2014. Intelligent conerol of a grid-connected wind-pho tovoltaic hybetid power systems. Electr. Power thergy Syst. $55,554-361$.

Huang, Q. Shi. Y.. Wang, Y., Lu, L, Cui, Y., 2015. Multiwturbine wind-solar hybrid system. Renesi. Energy $76,401-407$.

Instituto para la Diversificación y Ahorro de la Energía (IDAE), 2011. Instalaciones de Energía Solar Fotovoltaica, Pliego de Condiciones Técnicas de Instalaciones Conectadas a Red. PCT-C-REV, July (Spanish Normative)

Kono, T., Kogaki. T., 2013. Numerical investigation of wind conditions over a rectangther prism-shaped building for mounting small wind turbines. Wind Eng. $36,111-122$.

Kopp, G.A. Farquhar, 5. Morrison. M.], 2012. Aeredynamic mechanisms for wind loads on tilted roof-mounted. solar arrays. J. Wind Eng. Ind. Aerodyn. 111 $40-52$.

Ledo. I.. Koxasih, E. Cooper, P., 2011. Roof mounting site analysis for micro-wind turbint's. Retertir Energy 36, 1379-1391.

Liu, L.q. Wang, \%... 2009. The devedopment and application practice of windsolar energy intorid gentration systems in Chena. Renew. Sustain. Energy Rev. 13. $1504+1512$
Lu, L.. Ip, K.Y. 2009. Investgaton on the fessibilly and enhancement methods of whel prwer utilization in high rise buildings ot hong kang. Renew. Sustain.

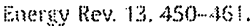

Meng. T., Hibi, K., 1998. Turbuent measuements of the flow fieid around a highrise buiding. I. Wind Eng. 76, 55-64 in lapanese

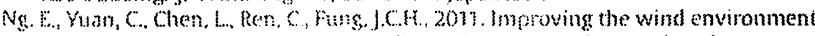
in ligh-density cities by understanding urban morphology and surface roughnessi a study in keng Kong. Landsc. Urban flan. 101, 59-74.

Panofisky. H. Dutton, J, 1984, Amospheric Turbulene. Wiley. New York

Pierik, J.T.G., Dekker, J.W.M., Braam, H., Bulder, B.H., Winkelaar, D., Larsen, G.C. et al., 1999. European wind turbine standards II (EWTS-II). In: Wind Energy for the Next Millennium. Proceedings. James and James Science Publishers, London.

Pope, 5. 2000. Turbulent Flows. Cambridge tiniversity Press, Cambridge.

Pratt. R.N., Kopp, G.A., 2013. Volocicy measurements around low-profile, tilted, solar arays mounted on lake flaterofs, tor wall momal wind directions. J. Wind Eng Ind Aerodyn, $123,226 \mathrm{~m} 238$.

Rampeni, R., Blocken, B., .012 . CF. simulation of cross-ventilation for a generic isolatco building: impac: of computatonal pataneters. Build. Environ. 53, $34 . \cdots 48$

Ricciardelli. F. Polmeno, 5. 2006. Some characteristic of the wind flow in the iower urban boundary laye: I. Wiad Fing. Ind Ae:odyn 94, 815-832.

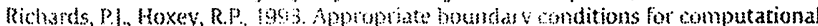
wind engineering models using the $k-\varepsilon$ tubulene model. J. Wind Eng. Ind. Aerodvn $46-47,145-15$

Roache, 1.]., 1909. Verificano of ades and calculatims. AlAA J. 36, 696-702.

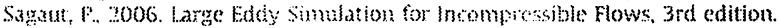
Springrer, Berlin.

Santiago, 1.L. Martilli, A. Martin F. $200 \%$ CF simmation of airfow over a regular

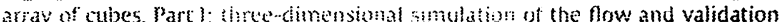

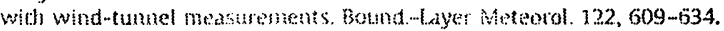

Soaperlas, A. Gilham. S., 2004 . Thematic Area 4 best practice advice for civil construction and HVAC ONET

Shademan, M., Balachandar, R., Baron. K.M., 2014. Denched eddy simulation of fow past an isolated inched solat puncl f. Fivis struct. 50, 217-230.

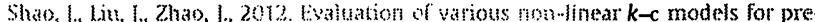
dicting wind flow drount an isolated high-rise buiding within the surface

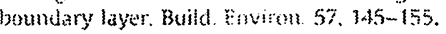

5cathopoulos, T., Zisis. 1. Xypnitou, E., 2014. Local and overall wind pressure and torec coefficionts for solat banels. I. Wind Eng hne Aerodyn. 125, 195-206.

Sumer, J. Watters. C.S. Massm, C. 2010. CFo in wind energy: the virtual, multiscale wind tumel. Energes 3, 980 -1013.

Sumner. J.. 2012. Towards linproved RANS $k-\varepsilon$ Modelling of Turbulent Incompres sible Flows for Wind Energy Applications (Ph.D. thesis). École de Technologie Supérieure, Université du Québec, Montreal.

Toja-Silva, F. Colmenar-Samm, A. Castro-Gil, M. 2913. Unban wind energy explotation systems: bchavour under multidiretonal flow conditions-

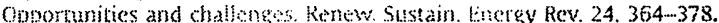

Toja-Silva, F., Peralta, C., Lopez, O., Navarro, J., Cruz, I., 2015. Roof region dependent wind potential assessment with different RANS turbulence models. J. Wind Eng. Ind. Aerodyn. 142, 258-271.

Tominaga. Y. Mochida, A. Miurakami. 5. Sawdiki. S. 20m8. Comparison of various revised $k-c$ models and LLES appled to flow around a high-rise building model with $7: 1: 2$ shape placed within the surface bomdary layer. I. Wind Eng. Ind. Aerodyn. 96.389m-11.

Tsuchiya, M., Murahami, S. Mochdi, A. Konde. K. ishida, Y. 1997. Development of a new $k-E$ model for tow and pressure fields around bluff body. J. Wind Eng. Ind. Acrodyn. 67-68. 160182

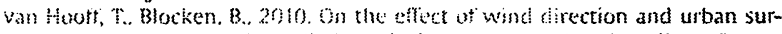
roundings on naturat vestitiston of a large semanchosed stadium. Comput 7ulds $39,1146-115$

Web: Contrib setDiscreteFields. OpenFOAM Wiki. (ivin:itopenfoamwikinet/index

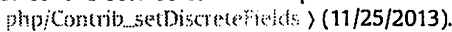

Web: Datasheet Solar Panel X21-345. Sunpower. (htopilus stupower.comjsites/ sunpowerfiles/media-libuarydata sheds/ds-x21-series-335-345-residentialsolar-panels-datasheet,pdi) $(09 / 17 / 2014)$.

Web: Datasheet T10 Solar Roof Tile. Sunpower. (intc) : tus.sunpowercorp.com/cs) Blobserver?blob

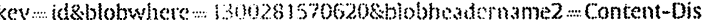
posirion zbobheadername 1 content.rypexblobheadervalue? $=$ inline

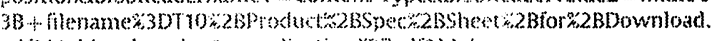

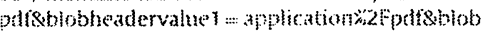
col :::.: uridatakblobtable ::: Mungoblobs) (09/17/2014)

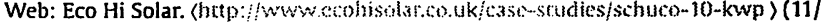
06/2014).

Web: Guidebook for practical applications of CFD to pedestrian wind environment around buildings. Architectural Institute of Japan. (hitcp://www.aij.or.jp/ipn/ publish/ctdguide/indek....htm) $(11 / 24 / 2013)$.

Web: OpenFOAM. (http:/ Whis openioamecom) $(11 / 24 / 2013)$

Web: SnappyHexMesh. OpenFOAM Wiki. (http:lojentoamwiki.netindex.php/ SnappyttexMesh) (11/27/2013).

Web: SnappyHexMeshDict. snappyWiki. (hrtps//sires google.com/site/snappywiki snappuhexmesh/snappytoxmeshotol (11/27/2013). 